\title{
Kapitel 7. \\ Die Ampelos-Episode im Rahmen des Gesamtkonzepts der Dionysiaka
}

Quand'ecco Atropo grida: „Il sommo Giove Più non vuol (Bacco) homai, che ti quereli.

Il Fato al pianger tuo con gratie nòue Dal'usato tenor distorna i cieli,

E'l gran decreto a cancellar si moue

Dele Parche implacabili e crudeli,

Onde malgrado dele stelle rëe,

Non passerà'l tuo amor l'acque Lethèe.

Viue Pàmpino viue, e benché sembri Spento de' suoi begli occhi il lume chiaro,

Vedrai tosto cangiati i vaghi membri

Nel buon licor, ch'altrui sarà sì caro.

Ti diè (so che con duol tene rimembri)

Morendo aspra cagion di pianto amaro, Per dar'al mondo tutto, horch'egli è morto,

Cagion poi di letitia, e di conforto.“

G. B. Marino ${ }^{1}$

\subsection{Die Erzählstruktur der Ampelos-Episode}

Eine zentrale Problematik der Nonnos-Forschung ist die Frage nach Komposition und erzählerischer Gestaltung der Dionysiaka. ${ }^{2}$ Bereits in den frühesten Abhandlungen zu Nonnos finden sich Einschätzungen und Bewertungen der Struktur des Epos, insbesondere der Bücher 10, 11 und 12. In den Interpretationen zu Beginn des 20. Jhs. wird die Liebesgeschichte zwischen Dionysos und dem Satyrn vielfach vor dem Hintergrund homerischer Dichtung gesehen; die Abweichungen von den Normen klassischer Erzähltechniken werden dem technischen Unvermögen des Dichters angelastet, das Fehlen von logischen Verknüpfungen und der sprunghafte Wechsel zwischen grundverschiedenen Szenen als Symptom spätantiker Dekadenz gelesen. Die Einschätzung des inneren Aufbaus der Ampelos-Episode als mangelhaft gipfelt in der Wertung des kosmologischen Teils mit den Horen und Helios als sekundärem Einschub, ebenso wurden das Kalamos-Karpos-Intermezzo und der Alternativmythos zur Genese des Weines sowie die sportlichen Wettkämpfe zwischen Dionysos und Ampelos als unvollendetes Stückwerk gesehen. Die ungewöhnliche Anlage und Aus-

1 Marino (2007) 596.

2 Zur Forschungsgeschichte der Ampelos-Episode siehe auch Kap. 1.4. 
führung bot überdies Anlass zu der These, der Dichter habe zwei unterschiedliche Ampelos-Mythen miteinander verschränkt.

Eine umfassende Revision erfuhr die Ampelos-Episode ab der zweiten Hälfte des 20. Jhs. durch Gennaro D’Ippolito, der auf die charakteristischen spätantiken Kompositionsprinzipien verwies: ${ }^{3}$ Grundlage der Struktur des Epos ist das Genus des Epyllions, welches mit dem Kontrastprinzip arbeitet und aus der Aufeinanderfolge gegensätzlicher Szenen, Wiederholungen und Variationen ein und desselben Motivs zu seiner Wirkung gelangt. Neue Interpretationen knüpfen an D’Ippolito an, wenn in den Motivparallelen zwischen der Ampelos-Episode und weiteren Büchern der Dionysiaka ebenso ein kompositorisches Prinzip wie in der Kosmologie gesehen wird. ${ }^{4}$ Durch die Verschmelzung unterschiedlicher literarischer Motive und Tendenzen in einer einzelnen Geschichte offenbart sich der Dichter der Ampelos-Episode als Repräsentant spätantiker ästhetischer Prinzipien.

Auf der Grundlage dieses Forschungsansatzes gilt es, im Folgenden Kompositionstechnik und Erzählstruktur der Ampelos-Episode im Detail zu erfassen. Ein Überblick über Szeneneinteilung und Strukturierungstechniken, Raum und Schauplatz sowie Orts- und Zeitangaben soll ebenso einen Einblick in Nonnos' narrative Techniken gewähren wie die Dokumentation der Vor- und Rückverweise auf die Ereignisse in den Büchern 10-12. Die Interpretationsgrundlage bilden außerdem die Kalamos-Karpos-Episode, die kosmologische Szene um Helios und die Horen sowie die Referenzen an den dionysischen Kult und die Frage nach Dionysos' göttlichem Status. Die Verbindungslinien zu weiteren Büchern der Dionysiaka beschließen dieses Kapitel.

Die Ampelos-Episode lässt sich in insgesamt zwölf Szenen untergliedern, die sich ihrerseits aus kleineren narrativen Abschnitten zusammensetzen, ${ }^{5}$ überwiegend autonome narrative Einheiten bilden und so prima facie aus sich selbst heraus erklärbar sind:

1. Am Ufer des Paktolos

2. Dionysos und Ampelos

3. Die Spiele

4. Ampelos' Hybris und Tod

5. Dionysos' Trauer

6. Trost durch Eros

6a. Kalamos und Karpos

7. Helios, die Horen und die Tafeln Nonn. D. 11,485-12,117

8. Trauer der Natur

9. Trost durch Atropos

10. Ampelos' Metamorphose
Nonn. D. 10,139-174

Nonn. D. 10,175-321

Nonn. D. 10,321-11,55

Nonn. D. 11,224-350

Nonn. D. 11,351- 485

Nonn. D. 11,369-481

Nonn. D. 12,117 - 137

Nonn. D. 12,138-172

Nonn. D. 12,173-206
Nonn. D. 11,56-223

3 Vgl. D’Ippolito (1964) 133-149.

4 Vgl. Giraudet (2005); Hernández de la Fuente (2008) 77f., 80-85.

5 Vgl. die Übersicht in Chrétien (1985) 81; Vian (1995) 28f., 90 f. 
11. Dionysos' Abschlussrede

12. Alternativmythos
Nonn. D. 12,207 - 291

Nonn. D. 12,292 - 397

Ungeachtet ihrer weitgehenden narrativen Selbstständigkeit werden die Szenen durch eine gemeinsame Erzähllinie zusammengehalten: das Schicksal des Ampelos und die daran anschließenden Reaktionen der anderen Figuren. Anhand dieser Linie entwickelt der Dichter Ereignisketten, verbindet einzelne Szenen und setzt sie miteinander in Beziehung, indem er eine Vielzahl an Bezugspunkten entwirft, von denen ausgehend sich ein regelrechtes Netz an gegenseitigen Referenzen aufspannt. Die Szenen 1-4 entwickeln das Ampelos-Drama vom heiteren Spiel der Satyrn am Fluss (1) über die Verbindung zwischen Dionysos und Ampelos $(2,3)$ bis zur Peripetie mit Hybris und Tod des Dionysos-Lieblings (4). Die übrigen Szenen der Episode (5-11) sind ausschließlich der Reflexion über das soeben Geschehene gewidmet: An die in aller Ausführlichkeit geschilderte Trauer des Dionysos (5) schließt nicht etwa Ampelos' Metamorphose, sondern Eros' Trostrede mit der Parabel über Kalamos und Karpos an (6), gefolgt vom Wechsel auf die Götterebene und der Ankündigung der unmittelbar bevorstehenden Verwandlung (7). Das Trauer-Thema (8) wird wie das Trost-Motiv in der Rede der Atropos (9) wieder aufgegriffen, bis schließlich in minutiöser Detailfreudigkeit der Akt der Verwandlung des Satyrn in einen Weinstock geschildert wird (10). Den Abschluss bildet die Reflexion über das Ereignis durch Dionysos selbst (11).

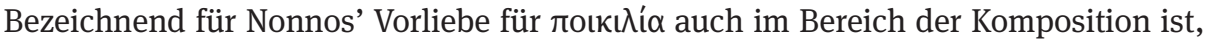
dass er die Ampelos-Episode mitten im 10. Buch beginnen lässt und die Wettspiele (3) sowie die Horen-Intervention (7) buchübergreifend gestaltet. Ein abrupter Einschnitt findet sich im Zusammenhang mit dem im Anschluss an den Ampelos-Mythos angefügten Alternativmythos zur Entstehung des Weines (12), eine Mythendoppelung, die aber ebenfalls im Lichte nonnianischer Erzähltechnik begreiflich wird. Typisch für das Prinzip der Variation ist der stetige Wechsel zwischen Szenen ausgelassener Heiterkeit und Hoffnung und solchen, die von geradezu melancholischer Trauer getragen werden: Das Spiel von Dionysos, Ampelos und den Satyrn im Paktolos $(1,2,3)$ ist durch lebensbejahenden Frohsinn gekennzeichnet, der die unzähmbaren dionysischen Kräfte vorwegnimmt $(11,12)$. Ampelos' Hybris und Tod korrespondieren mit seiner Metamorphose (10), beide Szenen erhalten in der Kalamos-Karpos-Erzählung eine Doppelung (6a). Das Motiv Trauer erscheint sowohl in den Klagereden des Dionysos (5) als auch in der Trauerszene der Natur (8), der Trost durch Eros (6) wird in der Trostrede der Atropos wiederaufgenommen (9). Eine kompositorische Linie lässt sich auch zwischen den prophetischen Textpartien ziehen, die Eros, die Tafeln der Harmonia und Atropos bieten $(6,7,9)$. Das sich aufspannende Geflecht von strukturellen und motivischen Entsprechungen schafft kompositorische Klammern, die die einzelnen Szenen zusammenhalten und zu einer narrativen Einheit verbinden. 


\section{Raum und Schauplatz}

Die Organisation der Erzählung erfolgt auch durch die Anlage und Gestaltung des Raums (Erzählraum, story-space) und des Schauplatzes (erzählter Raum, setting). ${ }^{6}$ Bereits zu Beginn der Ampelos-Episode wird Lydien als Ort des Geschehens bestimmt (Nonn. D.10,139), eine Landschaft, die als Kinderstube des Dionysos - die Göttin Rheia tritt dort als Erzieherin des Dionysos auf - wie auch des Ampelos gilt (vgl. den Phrygier

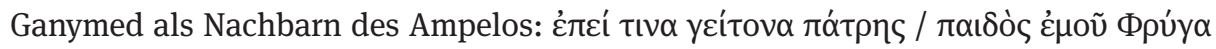

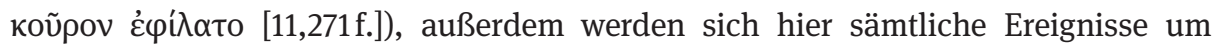
Dionysos und seinen Lieblingssatyrn abspielen. Zum Zweck der lexikalischen variatio

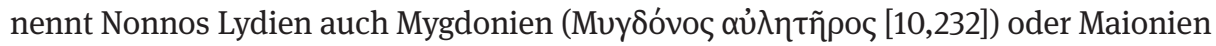

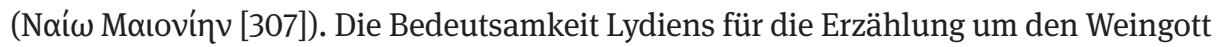
ist zudem aus der besonders ausführlichen Behandlung der Landschaft im Katalog der dionysischen Truppen ersichtlich (Nonn. D. 13,464-510). ${ }^{7}$ Nonnos bietet jedoch kein systematisches Bild Lydiens im Sinne einer vollständigen Kartierung der Landschaft, er hebt lediglich einzelne typische Landmarken hervor und reduziert die mögliche Summe dieser kleinasiatischen Landschaft auf einige ausgewählte Höhepunkte, die von außerordentlicher Wichtigkeit für seine Geschichte sind. Einer dieser Höhepunkte ist das Markenzeichen Lydiens schlechthin, der Tmolos, den Dionysos seinem eigenen Machtbereich zuordnet und dem Ida-Gebirge des Zeus entgegenstellt (Nonn. D. 10,257, 290, 293, 318; 11,338). Die waldige Gebirgslandschaft Lydiens und Phrygiens ist in der Folge Schauplatz für sämtliche Ereignisse um Dionysos und Ampelos (Nonn. D. 10,175177): Spiel und Jagd der beiden vollziehen sich im kaum zugänglichen Dickicht, im unwegsamen Gebirge und im baumlosen Flachland (Nonn. D. 10,219-277, 325-329; vgl. auch Nonn. D. 11,56f., 66, 74, 99f., 333), Wildheit und Unberührtheit dieser Landschaft werden durch die Anwesenheit wilder Tiere wie Panther, Bär und Löwe gekennzeichnet (10,250 f.; 11,63-70, 78-80, 337-350); die Begegnung mit dem Stier erfolgt ebenfalls im Gebirge, wo Ampelos auch den Tod findet (11,114, 156, 193, 195, 216, 296). Einschnitte in dieses natürliche Terrain in Form von künstlichen Strukturen gibt es, mit Ausnahme des Thyrsos, der Dionysos unter anderem als Wendemarke im Wettlauf dient (10,250, 327, 397; 11,238, 349, 353), und des Altars, auf dem der junge Hirsch stellvertretend für Ampelos geopfert wird (11,87, 92), nirgendwo. ${ }^{8}$

Diese Naturlandschaft wird als sehr fruchtbar beschrieben, wenn anlässlich der

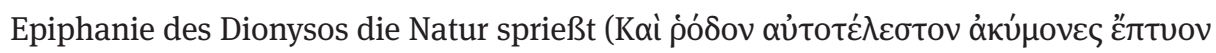
őx $\theta \alpha$ เ [Nonn. D. 10,171f.]), wenn in der Figurenbeschreibung des Ampelos der Dichter

6 Zur Definition siehe Dennerlein (2009) 127-132, 237, 240; de Jong (2012a). - Zu Landschaft und Raum in den Dionysiaka vgl. Shorrock (2013).

7 Vgl. Chuvin (1991) 99-111. - Dionysos wird am Ende des Epos im kleinasiatischen Phrygien seine Apotheose erfahren; Nonnos richtet die Ampelos-Episode auf den geographischen Mittelpunkt der Dionysiaka aus, den östlichen Mittelmeerraum, vgl. dazu Hadjittofi (2011).

8 Dieses Prodigium für Ampelos' Tod zeigt eine Drachenschlange, die sich aus felsigem Terrain in die bukolische Waldlandschaft begibt und ein Hirschjunges über einem Altar tötet (Nonn. D. 11,84-93). 


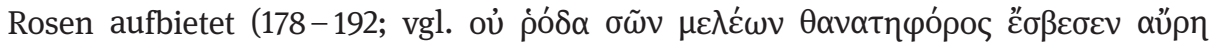
$[11,286])$, die die späteren Weintrauben vorwegnehmen, und wenn das Porträt des Satyrn sich auch als prophetische Ekphrasis des Weines lesen lässt. Erlesene Pflanzen sind an Schlüsselstellen der Episode zu finden, wenn etwa Eros den Sieger im Ringen mit einem Kranz aus Narzissen und Hyazinthen belohnt (Nonn. D. 10,358), Ampelos selbst den Stier mit Girlanden aus Rosen, Lilien, Narzissen und Anemonen (11,175178) und Dionysos den verstorbenen Ampelos mit Rosen, Lilien und Anemonen schmückt (235-237). Blumen und Kulturpflanzen wie Hyazinthen, Lorbeer, Rosen, Ölbäume und Getreideähren, die vorzugsweise Gegenstand bekannter Mythen sind (Nonn. D. 11,261; 12,110-113, 157, 207-211, 224, 231-244, 245-279), erfahren eine Erneuerung durch die dionysischen Pflanzen - die Ankündigung des Weines (12,155, 168), den ersten Wein und den Weingarten (173-187, 193-206) sowie den ersten Efeu (188-192). Die enge Verbundenheit der Vegetation mit dem Schicksal des Ampelos äußert sich in der Trauer von Pinie, Lorbeer und Ölbaum um den Getöteten (12,133137) sowie im Ersatz des von Nilwasser triefenden Ölzweiges der Herbsthore durch den Weinstock (11,510f., 515-519).

Der zweite symbolträchtige und narratologisch bedeutsame Schauplatz ist der Paktolos mit seinen Ufern, gleichsam ein Emblem Lydiens. Die gemeinsamen Unternehmungen von Dionysos und Ampelos umfassen auch den Aufenthalt am Paktolos

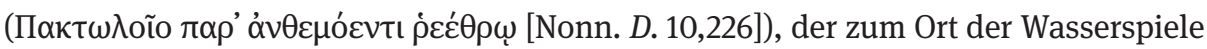
der Satyrn (141-174) und der Schwimmwettbewerbe wird und auch den narrativen Rahmen für den Ringkampf bildet (10,330-332, 380 -382; 11,312). Sein Wasser ist symbolisches Abbild und Vorstufe für den Wein, weshalb sich Ampelos und der Stier unmittelbar vor dem verhängnisvollen Ritt auch an einer Quelle aufhalten (Nonn. $D$. 11,161-166, 179-181). Die Besonderheit des Paktolos wird außerdem mehrmals durch Synkriseis mit anderen prominenten Flüssen - dem Geudis (Nonn. D. 11,36f.), dem Hermos (40), dem Eridanos (308f.) und dem Eurotas (12,165f.) - sowie im Rahmen der Klageszene der Natur hervorgekehrt, in der auch die Flüsse um Ampelos trauern (124130). Ein wichtiges narratives Pendant zum lydischen Fluss par excellence ist der Maiandros, der in der Kalamos-Karpos-Erzählung analoge Funktionen erfüllt, indem er ebenfalls als Schauplatz von sportlichen Agonen dient. ${ }^{9}$ In Kontrast zum stets positiv besetzten Paktolos wird der Maiandros jedoch von Beginn an als gefährlich und todbringend stilisiert, seine verschlungenen Windungen und sein abwechselnd überund unterirdisch verlaufendes Flussbett machen ihn zu einem zwielichtigen Ort, der

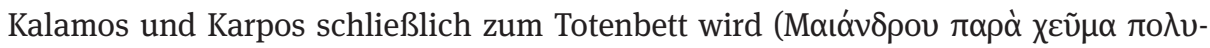

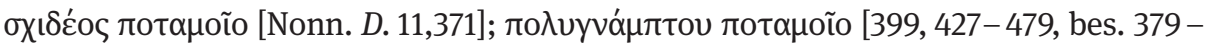
383]). ${ }^{10}$ Die Personifikation des Flusses stellt eine enge Verbindung zwischen Erzäh-

9 Für den Wettlauf sind Rennbahn (Nonn. D. 11,400), Start und Ziel (Ulme und Ölbaum als Landmarken [402]) festgelegt, für das Wettschwimmen die Schwimmbahnen (412) und die Strecke von Ufer zu Ufer (414f.).

10 Vervollständigt wird das Bild der verhängnisvollen Gewässer durch die Unterweltsflüsse Lethe, Acheron und Styx (Nonn. D. 11,322, 326; 12,143, 217, 220). - Für Text und Übersetzung der Stelle 
lung und Leser her, die nachfolgenden Geschehnisse um den Tod des Liebespaares erhalten eine Unmittelbarkeit, die die Erzählung nachvollziehbar, ja erlebbar macht. ${ }^{11}$

Der Tod des Ampelos erfolgt nicht am Fluss, sondern im Gebirge, wohin auch

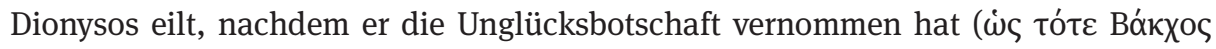

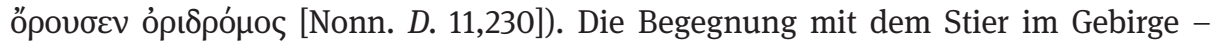
einem Ort der Kontemplation und des Zwiegesprächs mit der Gottheit - wird dem Satyrn zum Verhängnis. Die mit dem Dionysos-Mythos verbundene Gebirgslandschaft wird zum Schauplatz ausgelassener dionysischer Feiern und Kulthandlungen, zum Vollzugsort für Strafaktionen gegen Feinde der dionysischen Religion wie etwa Pentheus sowie zum Ort, an dem Ampelos die Epiphanie des Gottes in Stiergestalt und gleichzeitig seinen Tod erlebt. ${ }^{12}$

Der Raum der Erzählung wird auch durch Wegstrecken definiert, die von den Figuren zurückgelegt werden, wobei die räumlichen Verhältnisse nur an einigen wenigen Stellen klar festgelegt sind, so etwa in den Lauf- und Schwimmszenen, wenn Dionysos die Laufstrecke absteckt (Nonn. D. 10,393-397) und wenn die Positionen der einzelnen Läufer minutiös geschildert werden (402-412) sowie auch bei der Schwimmkonkurrenz (11,11, 14, 19, 21, 24, 38, 43-55), im Zuge derer die Schwimmbahnen $(51,53,55)$ und die Strecke von Ufer zu Ufer festgelegt werden (45). Mit Ausnahme der Spiele erfolgt die Darstellung von Ortswechseln nur selten, so etwa in den Jagdausflügen, die Dionysos und Ampelos unternehmen, oder im Lauf des Satyrn, der als Bote von Ampelos' Tod berichtet (Nonn. D.11,224f.), und auch im Lauf des Dionysos $\mathrm{zu}$ Ampelos ist Bewegung thematisiert (226-230). Dynamik ist ansonsten ausschließlich in mythischen exempla zu finden, die Figuren wie Pelops, Atymnios, Abaris und Ganymed in voller Bewegung zum Himmel emporschwebend oder durch die Luft fliegend zeigen (Nonn. D. 10,260 - 263;11,130 -135, 145, 148, 295), welche so gleichsam eine Apotheose erfahren und hierin Vorbilder für Ampelos sind. Der starke Gegensatz zwischen dem am Boden liegenden, sterblichen Satyrn (Nonn. D. 11,224, 230 f., 244, 313f.) und der Götterwohnung hoch oben im Olymp (272f.) wird schließlich durch die Metamorphose aufgehoben.

Ein besonderes Verhältnis zum Raum der Erzählung nehmen Beobachter-Figuren ein, die einen synoptischen Überblick über den Erzählraum und die einzelnen Schauplätze liefern. Diese Rolle kann Göttern und göttlichen Prinzipien zukommen, die sich auf einer der Erde übergeordneten Position befinden und so die Ereignisse der Erzählung überschauen, kommentieren und bei Bedarf auch in das Geschehen eingreifen. Dies gilt für Ate, die personifizierte Verblendung, sowie auch für die Mondgöttin Selene, welche beide mit Argwohn von Ampelos’ Hybris Notiz nehmen (Nonn. $D$.

siehe S. 212 f.; zur Charakteristik des Maiandros siehe auch Nonn. D. 13,563 - 565; zur metaphorischen Bedeutung vgl. Gigli Piccardi (2003) 791f. Anm. ad 379-384.

11 Die poetische Technik der Personifikationen von Räumen, Orten und Gegenständen findet sich schon in der hellenistischen Dichtung, vgl. Harder (2012) 94-96; de Jong (2012a) 16; de Jong (2012b) $52 \mathrm{f}$.

12 Zur Funktion von Berg und Gebirge bei Nonnos siehe Franchi (2011). 
11,113, 189). Einen allumfassenden, ja kosmischen Blick auf die Ampelos-Episode gewähren die vier Horen, die kein direktes Interesse an den Entwicklungen um Ampelos zeigen, sondern vom Himmel herabkommen (Nonn. D. 11,3), sich zum Palast des Helios am westlichen Rand des Okeanos begeben (485-487), um dort die Tafeln der Harmonia bezüglich eines geeigneten Attributs für die Herbsthore zu konsultieren $(12,1 \mathrm{f}.) .^{13}$ Der Schauplatz dieses himmlischen Anwesens wird durch einige wenige ausgewählte Objekte - Helios' Wagen (Nonn. D. 12,7 f.), die Futterkrippe der Pferde (14) und den Thron des Sonnengottes (15f.) - bestimmt. Im Zentrum der göttlichen PalastSzene stehen die vier Tafeln der Harmonia, die in der Art einer Bildergalerie an den Wänden angeordnet sind (Nonn. D. 12,30 - 32) und von der Herbsthore der Reihe nach abgeschritten werden (90f., 96, 103f.), wobei der Gang der Hore hier exakt der erzählten Zeit entspricht. Eine weitere Raumebene eröffnet sich durch die Ekphrasis auf den Tafeln selbst, die unterschiedliche Phasen der mythischen Weltgeschichte darstellt. Den auf den Tafeln skizzierten mythischen Figuren sind gelegentlich auch Schauplätze und Objekte zugeordnet (vgl. das Meer [Nonn. D. 12,46f.] und das Boot Deukalions [59-63]), eine Rolle spielen auch Verwandlungen in Pflanzen, Tiere und Naturphänomene, die gleichfalls für die Ampelos-Dionysos-Erzählung Relevanz zeigen (die Menschen gebärende Fichte [56], Argos als Vogel [70], Niobe als Felsen am Sipylon-Gebirge [79], Pyrrhos als Felsen [82], Thisbe in Wasser verwandelt [84], Atalante als Löwin [88]). Den Höhepunkt bilden zweifellos die Vorankündigung der Metamorphose in einen Weinstock sowie die Synkrisis des Weines mit anderen Pflanzen (Nonn. D. 12,97-102, 110 -113). Auf die Ampelos-Erzählung wird also nicht nur unmittelbar, sondern auch durch die auf den Tafeln genannten Landmarken, Figuren und Naturphänomene Bezug genommen, sodass die Verwandlung in einen Weinstock durch vergleichbare Entwicklungen in einer beglaubigten mythischen Vergangenheit vorgeformt ist.

Eine ähnliche Strategie wendet der Dichter in der Atropos-Rede an, indem er der Göttin Ortsnamen in den Mund legt, die ganz besonders mit dem Wein in Verbindung stehen: die Alltagswelt des Mittagstisches und des häuslichen Herdes (Nonn. D. 12,148, 150), die historischen Landschaften und Orte: Böotien, das in Nonn. D. 12,151 als Aonien bezeichnet wird und auf die Dithyramben-Dichtung Pindars anspielt, und Marathon, das als pars pro toto für ganz Attika steht und auf die Institution des dionysischen Theaters im klassischen Griechenland verweist (Nonn. D. 12,152). Nonnos macht Wein und dionysischen Kult zu Angelpunkten des täglichen Lebens wie auch der dichterischen Hochkultur Griechenlands.

Der für die Ampelos-Episode bestimmende Erzählraum Wald und Gebirge wird auch im Alternativmythos am Ende des 12. Buches aufgegriffen, wenn die göttliche Vorsehung, durch die der Wein in die Welt gelangt, besonders betont wird: Das vom

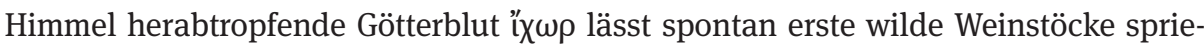

13 Der Gang der Horen dient als Rahmen für die Szene um Helios und die Tafeln, sie findet in Nonn. $D$. 12,115 - 117 mit dem Abzug der Göttinnen ihren Abschluss; zur Horen-Szene siehe S. 180 - 197. 
ßen, die einen idyllischen, von Menschenhand noch unberührten Garten hervor-

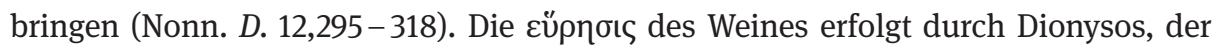
durch Zufall im Gebirge einer Schlange begegnet, die sich als seine Lehrmeisterin in der Weinpressung erweist (Nonn. D. 12,324). Der Schwerpunkt der weiteren Ausführungen liegt auf der technischen Beschreibung der ersten Weinproduktion (Keltertrog [Nonn. D. 12,331-334], Thyrsos als erste Sichel [335f.], Rinderhörner als Prototypen der Trinkbecher [360], Amethyst zur Wappnung gegen Trunkenheit [380 f.] $)^{14}$ sowie in der Darstellung des ersten Komos in der freien Natur (vgl. den Bergwald in Nonn. D. 12,373 sowie die Quellen in 375). Der vom Dichter zu Beginn der Episode komponierte Raum mit dem von üppiger Vegetation umgebenen Paktolos-Ufer gelangt mit der Existenz des Weines zu seiner Vollendung. Dem schon anfangs genannten und sukzessive weiterentwickelten Schauplatz Lydien wird mit der Begründung des dionysischen Kultes eine neue Gottheit zugewiesen, es bildet Ausgangs- und Endpunkt der Ampelos-Erzählung (Nonn. D. 12,397). Mit der maximalen geographischen Ausdehnung, die nicht nur den gesamten östlichen Mittelmeerraum und Indien umfasst, sondern auch die kosmische Ebene einbezieht, erhebt das nonnianische Epos einen Universalanspruch, indem es die Grenzen des in der Epik darstellbaren Raums auslotet, sich nicht auf eine menschlich-heroische Ebene beschränkt, sondern einen unbegrenzten Makrokosmos impliziert, vor dessen Hintergrund sich Dionysos als Gott etabliert. ${ }^{15}$

\section{Zeit und Zeitlichkeit}

Der Dichter ist an keiner Stelle der Ampelos-Episode darum bemüht, eine chronologisch schlüssige Abfolge der Ereignisse zu bieten, ${ }^{16}$ sondern es geht ihm vielmehr um die wirkungsvolle Inszenierung der Genese des Weinstocks. Die Verankerung der Episode in der Zeit erfolgt in Nonn. D. 10,139-142, wo Dionysos zu einem Jugendlichen herangewachsen ist und erstmals in der Erzählung als autonome Figur in Erscheinung tritt ("’ $v \varepsilon \varepsilon \varepsilon$, „er kam in die Blüte seiner Jahre“ [141]). Die unmittelbare Szenerie ist

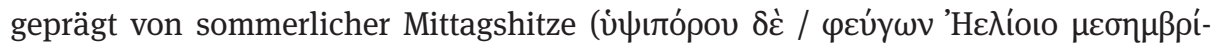

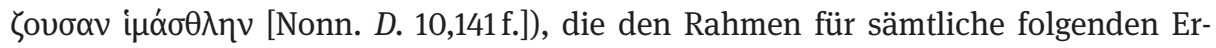
eignisse um Dionysos und Ampelos bilden wird.

Zudem hat die Reminiszenz an seine Kindheit, die Dionysos in seiner Rede im 10. Buch äußert, rhetorische Funktion: In Nonn. D. 10,294 erinnert sich Dionysos selbst an

14 Nonnos verbindet mit dem Amethyst eine der zahlreichen Etymologien, vgl. dazu Frangoulis (2003a) $435 \mathrm{f}$.

15 Zum veränderten Raumkonzept des Nonnos im Vergleich zum klassischen Epos vgl. Friedländer (1931) 44.

16 Vgl. Giraudet (2012) 1: „[...] le poète semble tout mettre en œuvre pour subvertir la séquence narrative de son poème par des effets de brouillage, de distorsion et de morcellement.“ Der Artikel Giraudets bietet einen narratologischen Zugang zur Paraphrase und zeigt Nonnos’ souveränen Umgang mit Zeitverhältnissen. 
das Schicksal des Zagreus, über das ihn seine Amme Rheia noch als Kind in Kenntnis

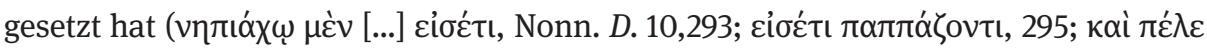

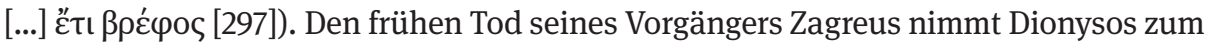
Anlass, jegliche Machtansprüche auf den Thron im Olymp auszuschlagen, um nicht auf seinen geliebten Satyrn verzichten zu müssen. Solche externen Analepsen Wiederaufnahmen, die sich auf Ereignisse außerhalb der Ampelos-Episode beziehen ${ }^{17}$ - finden sich auch in den zahlreichen Anspielungen auf die mythische Vergangenheit, etwa in den Vergleichsfiguren für Ampelos. Um die Zeitverhältnisse festzulegen, arbeitet der Dichter an diesen Stellen gelegentlich auch mit temporalen Konjunktionen und Adverbien: In Nonn. D. 10,310 - 320 nennt Dionysos Figuren aus dem Mythos, die

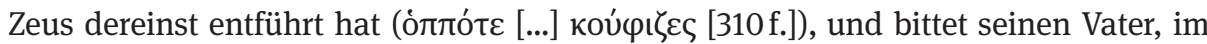
Falle des Ampelos Schonung walten zu lassen; und in Nonn. D. 11,130 - 154 zählt Ate mythische Beispiele für Jünglinge auf, denen es ihrer Meinung nach besser ergangen

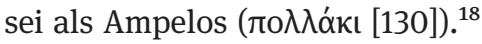

Mindestens von ebensolcher Bedeutung wie die Rückgriffe auf Bekanntes sind die internen Prolepsen, die Vorverweise auf Ampelos' Tod, seine Metamorphose, den Wein und den dionysischen Kult. ${ }^{19}$ Derartigen Anspielungen, die sich in den umfangreichen Prophetien der Ate, des Eros und der Atropos sowie in den Reden des Dionysos finden, ist meist das Tempus Futur oder der Modus Optativ gemeinsam: vgl. бò y

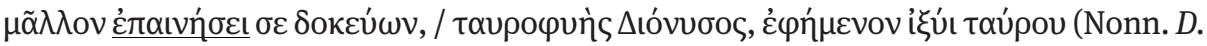

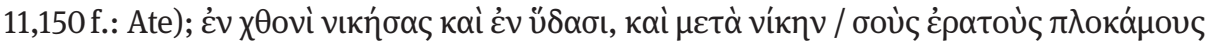

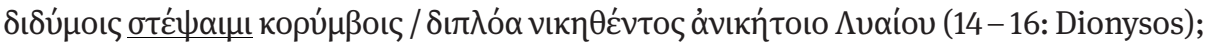

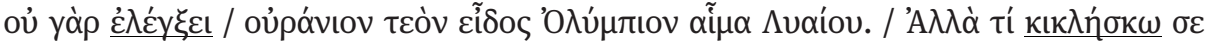

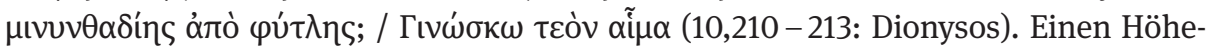
punkt erreicht der Blick in die Zukunft in der Rede der Atropos, in der gehäuft Futur-

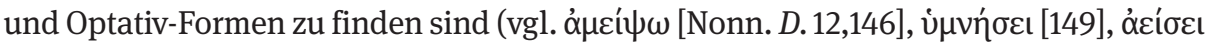

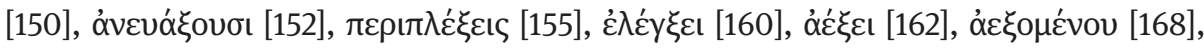

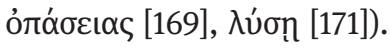

Äußerst subtil verfährt Nonnos mit den Verweisen auf das Kommen des Weines, indem er bereits in der Figur des Satyrn Aussehen und Eigenschaften der späteren Pflanze reflektiert: ${ }^{20}$ Ampelos schlingt sich im Ringkampf genauso um Dionysos, wie

$17 \mathrm{Zu}$ dieser narratologischen Kategorie vgl. de Jong (2007) 3-8.

18 Die Erzählebene mit Dionysos und Ampelos ist ferner durch Temporaladverbien und Konditio-

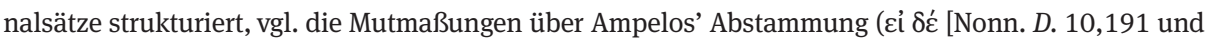

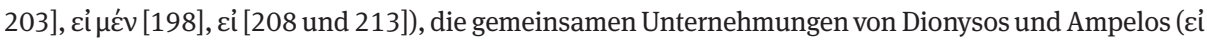

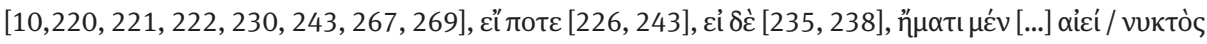

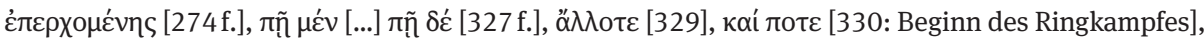

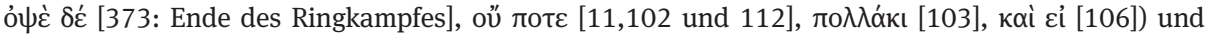

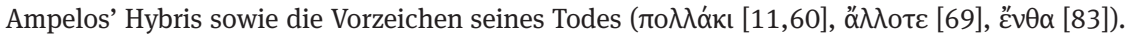

19 Eine ähnliche poetische Technik der oftmals subtilen Vorankündigung von Ereignissen verfolgt Nonnos mit der Kadmos-Figur, vgl. Frangoulis (2013); zu den Vorverweisen und Orakeln in den Dionysiaka vgl. Lightfoot (2014).

20 Vgl. dazu Kap. 3.3. 
sich der Wein an anderen Pflanzen emporranken wird (Nonn. D. 10,347-350), der Stier besprengt Ampelos mit Quellwasser, was die Notwendigkeit der Bewässerung der kultivierten Weinstöcke vorwegnimmt (11,161-166), und der vom Blut rote Leichnam

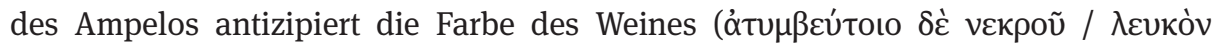

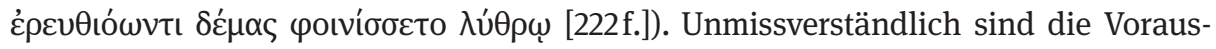
deutungen in dem von Dionysos interpretierten Vorzeichen, welches das blutige Opfer eines jungen Hirsches zum túroৎ für die Libation mit Wein kürt (Nonn. D. 11,83-98): ${ }^{21}$

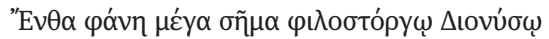

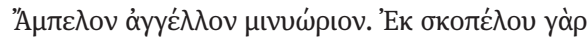

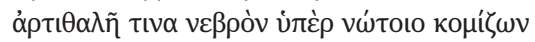

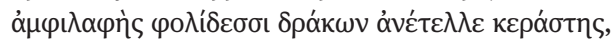

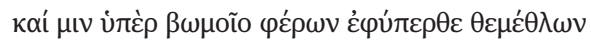

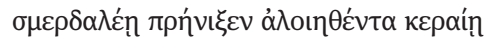

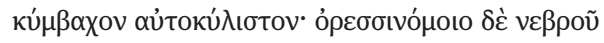

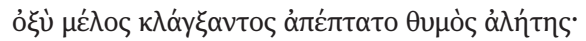

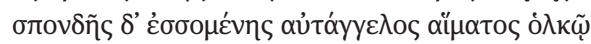

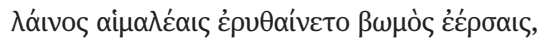

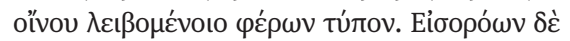

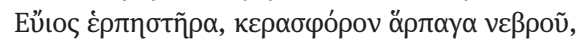

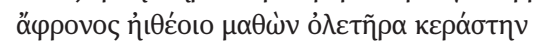

95

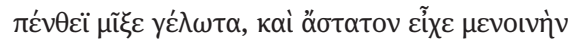

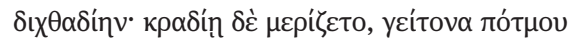

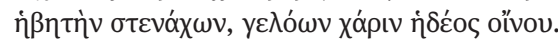

Da erschien dem liebenden Dionysos ein großes Zeichen, die Botschaft für Ampelos' kurzes Leben: Denn von der Höhe herab (85) brachte auf ihrem Rücken eine dicke, gehörnte Schlange mit Schuppen ein eben erst erblühtes Kitz, führte es zu einem Altar auf einem Sockel, wand sich mit blutigem Horn zuerst am Kopf um das geschlagene Jungtier wie von selbst bewegt herum. Und vom berggenährten Kitz (90) ertönte ein gellender Laut, und sein Lebensmut entfloh ihm und irrte davon. Dass es ein Opfer geben werde, dessen war durch den Blutstrom der steinerne Altar Vorbote. Er färbte sich rot von den Blutströmen und trug das Abbild der Weinspende schon in sich. Und als Euios das Kriechtier, den hörnertragenden Räuber des Kitzes, sah, (95) da erkannte er das gehörnte Verderbnis für den törichten Jüngling. Er mischte der Trauer Lachen bei, hatte immerzu ein zwiefaches Verlangen und war im Herzen gespalten: Über den Jüngling, seinem Ende nahe, seufzte er, aber er lachte auch aufgrund des süßen Weines.

Auch das Gärtner-Gleichnis in der an Dionysos gerichteten Rede des Eros birgt einen

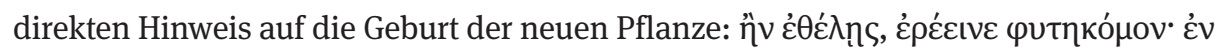

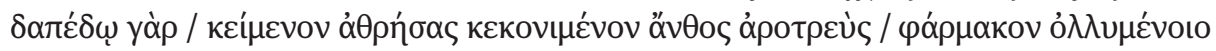

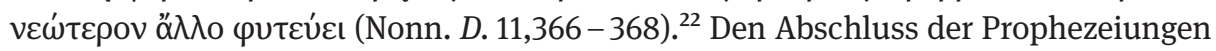
bildet die letzte Rede des Dionysos, in der ebenfalls eine Reihe von Futur-Formen zu

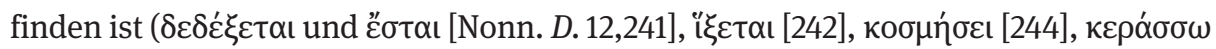

21 Das Prodigium kündigt auch die Opferung des Stieres im Rahmen des dionysischen Kultes an; vgl.

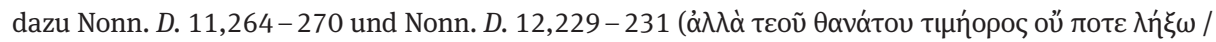

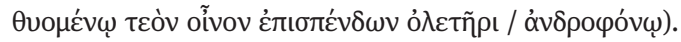

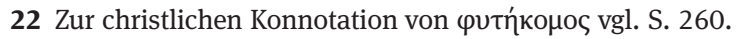


[271]). Der Ampelos-Mythos endet so, wie er begonnen hat, mit dem Verweis auf die Jahreszeit des Hochsommers, die Voraussetzung für den Reifungsprozess der Trauben (Nonn. D. 12,285-289). Nonnos' Selbstreferenz an dieser Stelle greift den locus

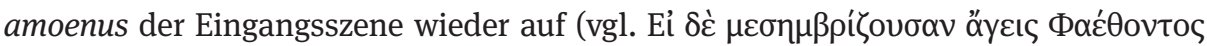

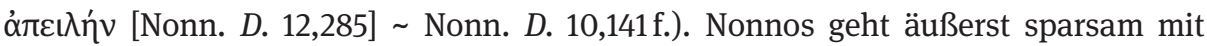
konkreten chronologischen Angaben um und setzt diese nur an Angelpunkten der Erzählung. Die einander entsprechenden Zeitangaben am Anfang und am Ende der Ampelos-Episode dienen als kompositorische Klammer, die die Erzähleinheit gewährleistet, wobei nirgendwo ein exaktes chronologisches System geschaffen, sondern vielmehr die Genese des Weines als Ergebnis einer mythisch-historischen Evolution inszeniert wird, die vor Urzeiten fixiert wurde.

Um den Gedanken eines zyklischen Entwicklungsprozesses besonders anschaulich zu gestalten, begnügt sich der Dichter nicht mit einer einfachen Vorhersage, sondern bietet eine Kette von mystischen Prophetien, die allesamt auf das Kommen des Weines abzielen. ${ }^{23}$ Den Höhepunkt dieser Orakel stellt zweifelsohne die HorenSzene zu Beginn des 12. Buches dar, die selbst von den Zeitangaben anlässlich des Ganges der Horen zum Palast des Helios gerahmt ist: ${ }^{24}$ Der Aufbruch der vier Göttinnen

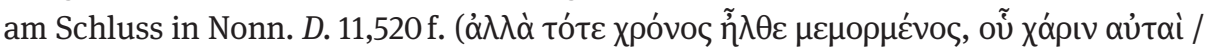

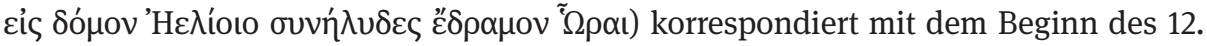
Buches, doch die Szene ist insofern weiterentwickelt, als nun Zielort der Reise und zeitlicher Rahmen genannt werden (Nonn. D. 12,1-20):

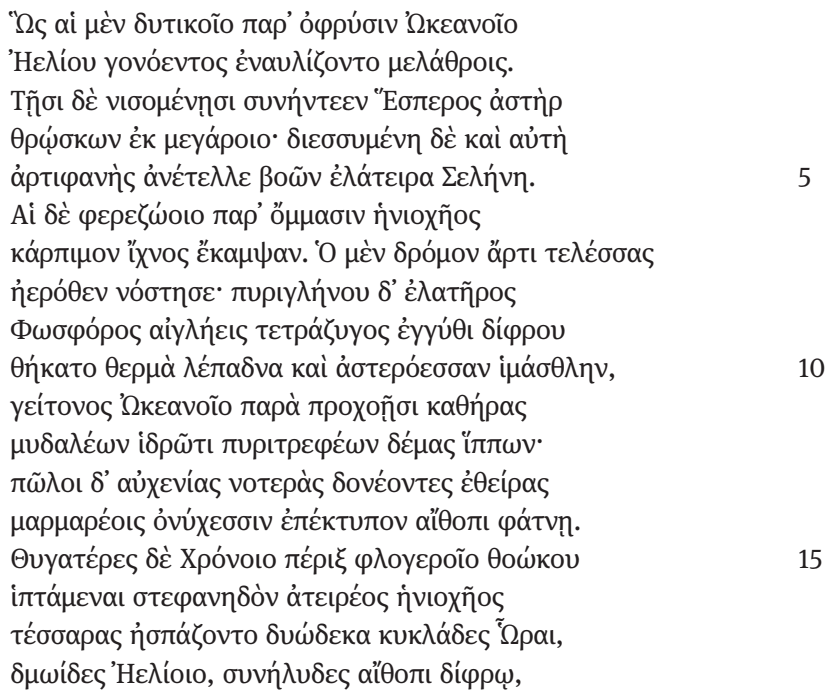

23 Zum Einfluss der Orakelpoesie auf die spätantike Dichtung und auf Nonnos vgl. Ruíz Pérez (2002); Hernández de la Fuente (2013) 249-252.

24 Vgl. Roberts (1985) 208f., der auf die Verwendung des epischen Stilmittels der Zeitangabe in der spätantiken lateinischen Bibeldichtung verweist. 


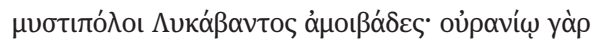

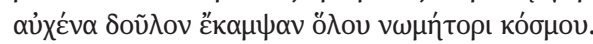

\begin{abstract}
So suchten sie Zuflucht am westlichen Rand des Okeanos im Haus des Ertrag bringenden Helios. Und als sie ankamen, traf der Abendstern auf sie, der oben aus dem Haus eilte. Und auch sie selbst stürzte los, (5) die gerade eben Erschienene, und ging auf, die Lenkerin der Rinder, Selene. Und die anderen hemmten beim Anblick des Leben spendenden Wagenlenkers ihren Früchte bringenden Schritt. Der [sc. Helios] hatte soeben seinen Lauf beendet und kehrte heim aus der Luft. Und vom Wagenlenker mit feurigen Augen legte Phosphoros, der Strahlende, nahe dem Viergespann (10) die noch warmen Zügel und die sternenbesetzte Peitsche nieder, und reinigte in den Fluten des nahen Okeanos den schweißnassen Leib der feuergenährten Pferde. Die Fohlen schüttelten die Nacken und ihre triefenden Mähnen, und mit ihren strahlenden Hufen schlugen sie auf die glänzende Krippe. (15) Die Töchter des Chronos flogen um den feurigen Sitz des unermüdlichen Wagenlenkers kranzförmig herum, und die vier empfingen die zwölf periodisch wiederkehrenden Horen, die Dienerinnen des Helios, Begleiterinnen des strahlenden Wagens und Mystinnen des Jahres, abwechselnd eine nach der anderen. Denn vor dem Himmlischen, (20) dem Lenker des ganzen Kosmos, beugten sie ihren dienenden Nacken.
\end{abstract}

Die allabendliche Heimkehr des Sonnenwagens wird durch die präzise Beschreibung der beteiligten Figuren und ihrer Aktionen - Selene, Helios, Phosphoros und das Pferdegespann - besonders anschaulich zu einer eigenen Erzähleinheit und steht in Kontrast zum knappen Verweis auf den Aufbruch der Horen am Ende des 11. Buches. Die traditionelle epische Zeitangabe Abend und Einbruch der Nacht wird zu einer kleinen Geschichte ausgebaut, deren Protagonisten allesamt göttlich-astronomische Größen sind, die Tag oder Nacht bezeichnen. Die Dauer des Besuches der Horen bei Helios ist aus dem Ende der Szene ersichtlich, wenn die Jahreszeiten den Palast bei

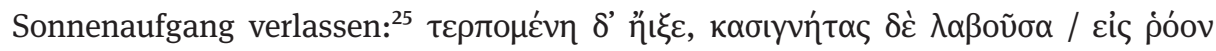

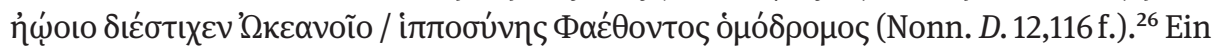
chronologischer Ablauf des Besuches wird zudem durch den Spaziergang der Herbsthore von einer Tafel zur nächsten suggeriert, indem der Leser gleichsam in Echtzeit von Tafel zu Tafel schreitet und deren Inhalte zugleich mit der Hore liest (кaì

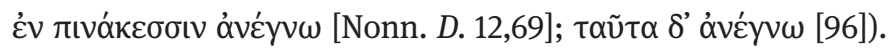

Die $\sigma u ́ \mu \beta 0 \lambda \alpha \mu \alpha v \tau o \sigma u ́ v \eta \varsigma$, die Prophezeiungen auf den Tafeln der Harmonia (Nonn. D. 12,92), konstituieren sich aus Genealogien und Sukzessionsmythen, die ebenfalls eine chronologische Abfolge implizieren: Die beiden ersten Tafeln bieten einen Ausflug in die mythische Urgeschichte und erzählen von den Göttergenerationen bis zur Machtübernahme durch Zeus, der Geburt der Menschen sowie der deukalionischen Sintflut (Nonn. D. 12,41-51; 52-63). Der Regress in der Zeit bis auf den Schöpfergott Ophion (Nonn. D. 12,44) und den orphischen Phanes, der als Autor der Tafeln genannt wird (34), schafft eine doppelte Verankerung des Ampelos-Mythos in der von Nonnos konstruierten mythischen Vergangenheit. Der Dichter komplettiert

25 Vgl. auch die Schildbeschreibung in Nonn. D. 25,380 - 572; Byre (1976) 179.

26 Nonnos' gestalterische Vielseitigkeit zeigt sich in der dichterischen Umsetzung der Zeitangabe Morgen, die einmal knapp mit nur einem einzigen Wort, einmal im Rahmen einer ausführlichen Ekphrasis erfolgen kann, vgl. D’Ippolito (2003) 513-516. 
seinen chronologischen Kosmos, indem er auf der dritten Tafel einen Blick in die

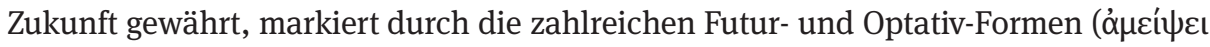

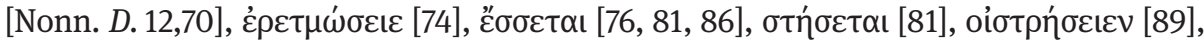

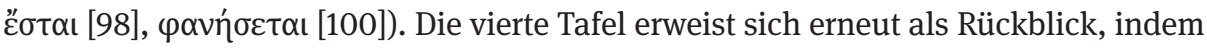
die Genese des Weines nun nicht als Prophezeiung, sondern als eine seit alters her festgesetzte Entwicklung präsentiert wird (Nonn. D. 12,110-113; vgl. das Verb

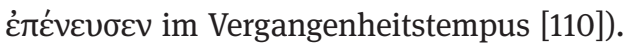

Trotz der vielen Bezüge auf eine mythische Zeitenfolge erhält der Leser dennoch nicht den Eindruck einer konsequenten Chronologie im Sinne einer klaren Trennung von Vergangenheit, Gegenwart und Zukunft. Nonnos kommt es nirgendwo auf die Realisierung eines zeitlichen Kontinuums an, vielmehr ist seine Poetik, die den ästhetischen Prinzipien der Spätantike verpflichtet ist, von narrativen Pausen, literarischen Anachronismen und kompositorischen Disharmonien durchzogen, ja von einer regelrechten Achronie geprägt: „[...] bei Nonnos ist die Zeit aufgehoben. Nichts geschieht wirklich nacheinander, alles existiert zugleich. Die Einzelheiten sind zeitlose Fixpunkte; man darf nie fragen, wann etwas geschah.“27 Mit den vier Tafeln der Harmonia konstruiert Nonnos eine chronologische Zusammenschau, ein fiktives mythisches Zeitbild mit dem Wein und Dionysos als Höhepunkt: „Tutto si riflette in tutto, il passato nel futuro, il futuro nel passato, entrambi nel presente, il mito nella storia, la storia nel mito.“28 Die Betrachtung der Tafeln durch die Hore transferiert Vergangenheit und Zukunft in die Gegenwart der Erzählung und fügt das zeitliche Nacheinander der Mythen durch die simultane Darstellung, durch die gleichsam physische Präsenz der Tafeln zu einem synchronen Gesamtbild, das die menschlich erfassbare Dimension der Zeit weitgehend ausschaltet und eine immerwährende „Weltzeit“29 dagegen setzt. Dieses Verwischen der Grenzen zwischen Vergangenheit, Zukunft und dem Hier und Jetzt der Erzählung wird im Aufgebot von Figuren manifest, die Zeit oder Zeitabschnitte personifizieren oder für den zeitlichen Ablauf verantwortlich sind. Dazu gehören die vier Horen der Jahreszeiten, ${ }^{30}$ die zwölf Stundenhoren (Nonn. D. 12,15-20), die Himmelskörper und Gestirne, die den Lauf der Zeit regeln Helios (12,2, 5, 30, 36, 91), der Abendstern (12,3), der Morgenstern Phosphoros (12,9), Selene $(12,5)$ und die Sternbilder Löwe und Jungfrau $(12,38)$ - ebenso wie die göttlichen Instanzen Aion (12,25) und Phanes (12,34). Die Konzentrierung dieser Figuren an einer einzelnen Stelle betont deren Wichtigkeit im Hinblick auf das Verständnis der Am-

27 Bogner (1931) 183; vgl. auch Abel-Wilmanns (1977) 113-120; Agosti (1995) 143 spricht im Zusammenhang mit der literarischen Technik der Ekphrasis von einem „gusto per la pausa descrittiva“; vgl. auch Hernández de la Fuente (2008) 26, der die Dionysiaka als „epopeya atemporal en forma de compendio mitológico y literario“ charakterisiert; über die Synchronität der Prophezeiungen auf den Tafeln der Harmonia in Buch 12 auch Lightfoot (2014) 51: „Nonnus' tablets are records of the cosmos’ entire history, past, present, and future.“

28 Averincev (1988) 205.

29 Friedländer (1931) 44.

30 Zum Epitheton $\Lambda$ $\alpha_{\alpha} \beta \alpha$ s für die Horen vgl. auch Nonn. P. 18,65; Livrea (1989) 141. 
pelos-Episode: Die Gottheiten stellen den zyklischen Verlauf der Zeit und die unablässige Wiederkehr analoger mythischer Kräfte in den Vordergrund. ${ }^{31}$ Da er die Genese des Weines als Erfüllung eines uralten göttlichen Plans stilisiert und mit zahlreichen Vorbildern und Antitypen in der mythischen Tradition ausstattet, erhebt der Dichter für seinen Ampelos-Mythos einen Absolutheits-, ja Ewigkeitsanspruch.

Vergleichbarer narrativer Strategien bedient sich Nonnos auch im Alternativmythos am Ende des 12. Buches. ${ }^{32}$ Die Erzählung wird ausdrücklich als „älter“ deklariert

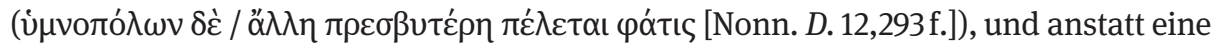
Abfolge von Prophezeiungen wie in der zuerst geschilderten Version der Entstehung des Weines zu bieten, verkürzt Nonnos und bietet nur ein Minimum an Informationen:

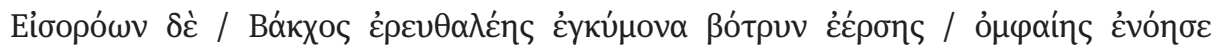

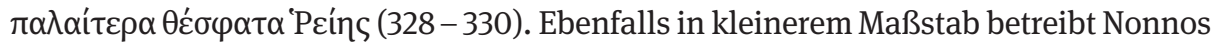
die Verschränkung der Zeitebenen, indem er die erste Kelterung und Verkostung des Weines durch Dionysos und die Satyrn zum Fundament für den zukünftigen Kult

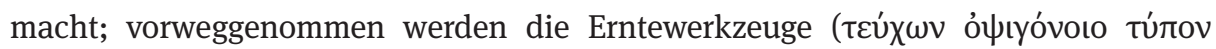

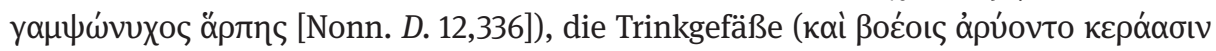

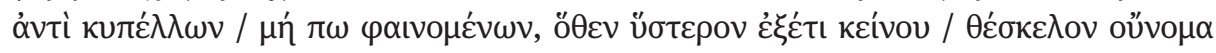

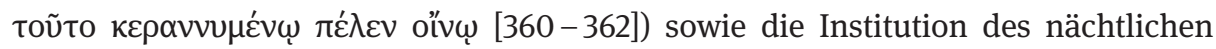

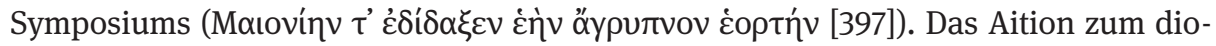
nysischen Kult überträgt „den älteren Mythos der Hymnendichter“ in die Gegenwart der Erzählung und bezieht zugleich künftige Entwicklungen mit ein (vgl. óభıyóvoı und ǔotepov).

Nonnos spielt in der Ampelos-Episode mit den Möglichkeiten der poetischen Umsetzung von Zeit und zeitlicher Abfolge, indem er seine eigene Erzählung im Kosmos der griechischen Mythologie verankert und deren Ausgang durch mehrfache Orakel und Prophezeiungen von höchster Stelle absichert. Gerade durch die Verweigerung eines exakten, chronologischen Systems und durch die Konzentration auf die poetische Umsetzung des Prinzips der zyklischen Wiederkehr der Zeit wertet er den Ampelos-Mythos gegenüber der mythischen Tradition auf. Diese Verankerung der neuen Erzählung in tatsächlichen oder auch rückwirkend konstruierten Traditionen zeugt vom Selbstverständnis eines Dichters, der sich als Erbe hellenischer Literatur und Kultur versteht.

\subsection{Kalamos und Karpos}

Die Verortung der Ampelos-Erzählung in einem mythischen Makrokosmos ist auch ein wesentliches Element in der Liebesgeschichte zwischen Kalamos und Karpos im 11.

31 Vgl. Turcan (2011) 27, 37, 62f., 70.

32 Siehe dazu Kerényi (1994) 51-53. 
Buch. ${ }^{33}$ Um seiner Trostrede an Dionysos (Nonn. D. 11,356-481) Nachdruck zu verleihen, erzählt Eros einen Mythos, der ähnlich wie die Geschichten um Ampelos in der antiken Literatur kaum bezeugt ist. Lediglich bei Servius in seinem Kommentar zu Vergils Eklogen finden sich Informationen (Serv. in ecl. 5,48: nec calamis solum aequiperas, sed voce magistrum): ${ }^{34}$

NEC CALAMIS S. AEQ. S. V. M. videtur allegoria quasi ad Theocritum et Vergilium respicere: hinc est ,tu nunc eris alter ab illo". fabula de calamo talis est: veteres Zephyro vento unam ex horis coniugem adsignant, ex qua et Zephyro Carpon filium pulcherrimi corporis editum dicunt. quem cum Calamus, Maeandri fluvii filius, amaret, a Carpo mutua vice etiam ipse adamatus est. sed Carpos cum in Maeandrum fluvium cadens esset extinctus, Calamus, patrem propter hoc scelus aversatus, aufugit rogavitque Iovem, ut finem suis luctibus daret sibique mortem praestaret, ut amato post obitum iungeretur. quem miseratione Iuppiter ductus in harundinales calamos verti iussit, qui semper circa oras fluminum nasci solent, Carpon vero in fructus rerum omnium vertit, ut semper renasceretur.

Nonnos bietet eine in den Grundzügen vergleichbare Geschichte, führt jedoch einige Modifikationen durch, ${ }^{35}$ indem er Elemente vergleichbarer Mythen um junge Götterlieblinge einarbeitet (Lakos, Kyparissos und Hyakinthos [Nonn. D. 11,363-365]) und Motive wiederholt, die bereits aus der Ampelos-Erzählung bekannt sind: Porträts der beiden Protagonisten (Nonn. D. 11,369 - 399) sowie Wettspiele - einen Wettlauf (400 405) und einen Schwimmwettbewerb (406-426). ${ }^{36}$ Bereits die Vorstellung der Figuren orientiert sich lexikalisch und motivisch an der Erzählung um Dionysos und Ampelos (Nonn. D. 11,369-399):

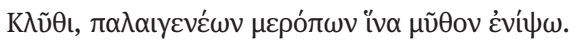

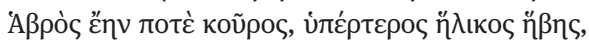

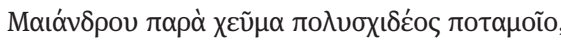

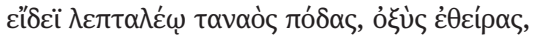

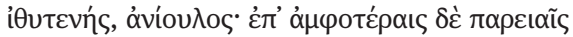

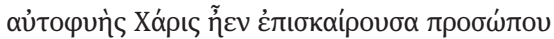

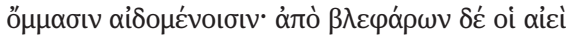

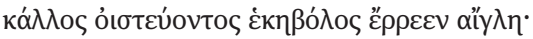

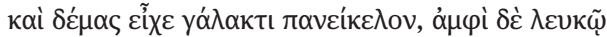

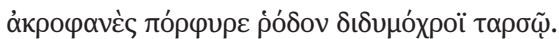

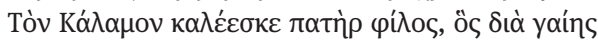

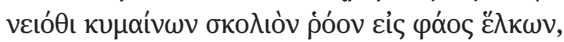

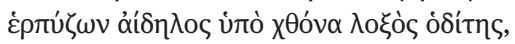

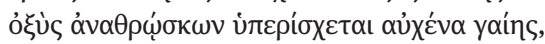

33 Zur Kalamos-Karpos-Episode vgl. Ouwaroff (1817) 38-41; D’Ippolito (1964) 146-149; Gigli Piccardi (2003) 737 f.; Nizzola (2012) 60-62, 66 -68; Frangoulis (2014) 97. - Gerstinger (19431947) 85 f. sieht in der Trostrede des Eros eine Reminiszenz an die in den Metamorphosen des Apuleius erzählte Geschichte über Amor und Psyche, vgl. Frangoulis (2014) 11 Anm. 15.

34 Vgl. Vian (1995) 19; Gigli Piccardi (2003) 738, 790 Anm. ad 371; Gigli Piccardi (2003a) 374; Hernández de la Fuente (2008) 84.

35 Vgl. D'Ippolito (1964) $148 \mathrm{f}$.

36 Zur Komposition der Kalamos-Karpos-Episode vgl. Vian (1995) 19-25. 


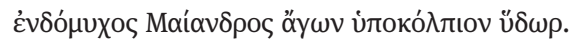

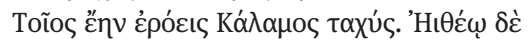

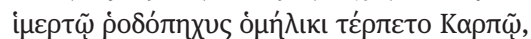

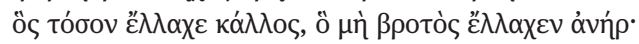

عi yò

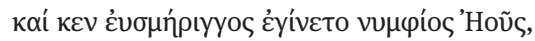

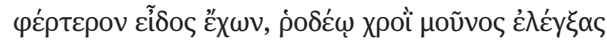

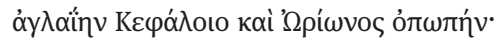

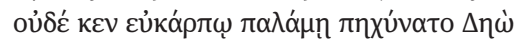

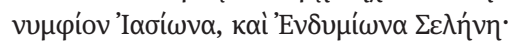

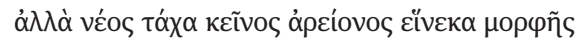

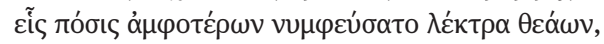

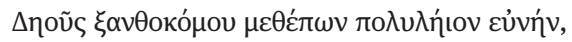

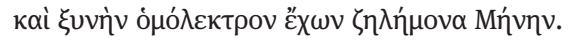

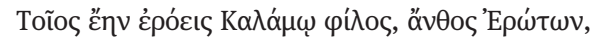

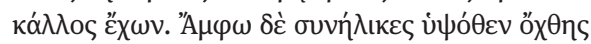

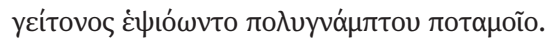

Höre, damit ich dir eine Erzählung von früheren Menschen berichten kann: (370) Es war einmal ein schöner Knabe, stärker als es seinem Alter entsprach, am Strom des Maiandros, des vielarmigen Flusses, von zarter Gestalt, mit langen Beinen, spitzborstig an den Haaren, von gerader Haltung, bartlos. Und an beiden Wangen war ein angeborener Liebreiz, der aus dem Gesicht mit scheuen Augen hervorsprang. (375) Und von den Blicken ließ immer ein ferntreffender Glanz seine Schönheit erstrahlen. Er hatte eine Haut wie Milch, und um das Weiß befand sich nur ganz außen an der Spitze der doppelfarbenen Füße ein purpurnes Rot. Kalamos nannte ihn sein lieber Vater, der unterirdisch (380) durch das Land fließt und seine wellige Strömung wieder ans Tageslicht führt, der als Wanderer auf Umwegen unsichtbar unter der Erde dahinkriecht und abrupt wieder an die Oberfläche kommt, seinen Nacken wieder oberirdisch hält und drinnen in seinem Schoß Wasser führt: Maiandros. So reizend wurde Kalamos bald. Und am Jüngling, (385) seinem begehrenswerten Altersgenossen Karpos, erfreute sich der Rosenarmige, der bald zu einer solchen Schönheit gelangte, wie sie sonst kein sterblicher Mann jemals erreichte. Denn wenn dieser Knabe unter den früheren Männern gelebt hätte, dann wäre er der Bräutigam der schöngewandigen Eos gewesen, hätte ein noch schöneres Aussehen gehabt und mit seiner rosigen Hautfarbe sich als Einziger mit dem (390) strahlenden Antlitz des Kephalos und des Orion gemessen. Und Deo hätte nicht mit ihrer Früchte tragenden Hand Iasion als Bräutigam umarmt, und Selene nicht den Endymion. Sondern jener Knabe hätte aufgrund seiner schöneren Gestalt schnell als einziger Gatte Hochzeit mit beiden Göttinnen gefeiert; (395) er wäre der blonden Deo aufs Lager in den Saatfeldern gefolgt und hätte dasselbe Bett mit der eifersüchtigen Mene geteilt. Einen so reizenden Altersgenossen hatte Kalamos, eine Blüte der Eroten, voll Schönheit. Und beide amüsierten sich oben am Ufer des benachbarten Flusses mit den vielen Strudeln.

Auch die Kalamos-Karpos-Episode wurde in der frühen Forschung als sekundäre Zutat eingestuft: Für Paul Collart stellte sie einen Einschub dar, der auf die Tatsache zurückzuführen sei, dass Nonnos in seiner Ampelos-Episode aus unterschiedlichen Mythentraditionen geschöpft habe. ${ }^{37}$ Diese Ansicht wurde jedoch spätestens durch Gennaro D’Ippolito zurückgewiesen, der auf der Basis seiner Epyllion-Theorie der Episode erstmals eine kompositorische Bedeutung einräumte, die sich vor allem in

37 Vgl. Collart (1930) 106f.; siehe auch Keydell (1932) 181f. (493f.) und Keydell (1936) 907, 910. 
ihrer engen Verbindung zur Ampelos-Erzählung äußert. ${ }^{38}$ Tatsächlich stellt die Kalamos-Karpos-Episode ein Paradebeispiel für Nonnos’ Technik der „imitatio cum variatione“ “ ${ }^{39}$ dar, wobei der Dichter nicht auf seine Vorgänger, sondern auf sein eigenes Werk zurückgreift.

Das Porträt des Satyrn Ampelos (Nonn. D. 10,175-192) teilt eine Reihe von ekphrastischen Topoi mit der Beschreibung von Kalamos und Karpos: ${ }^{40}$ Die Charakterisierung der äußeren Erscheinung in Form eines Katalogs der einzelnen vorzüglichen Körperteile ist schon aus dem Ampelos-Porträt bekannt und begegnet bei Kalamos und

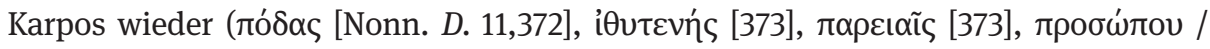

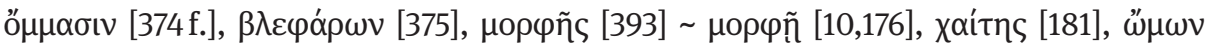

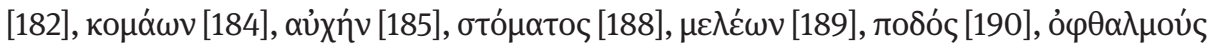

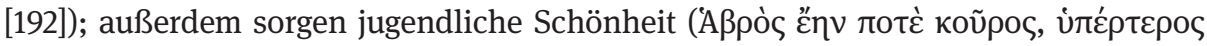

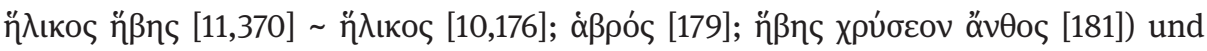

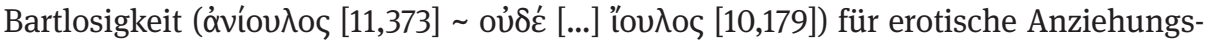

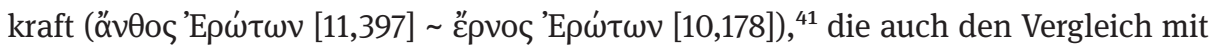

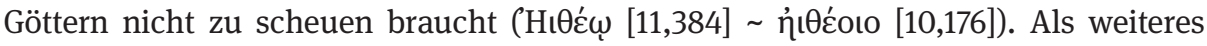
erzählerisches Element kommt das Glanz-Thema hinzu, welches die Vorzüge des Beschriebenen ebenso unterstreicht wie das Motiv, wonach die Schönheit wie ein Pfeil in

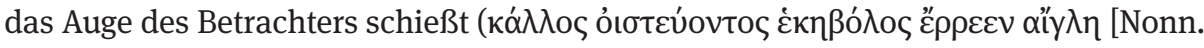

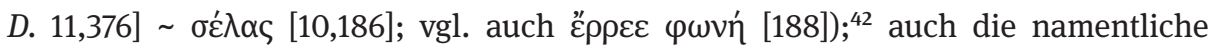
Nennung Selenes ist der Glanz-Thematik zuzuordnen (Nonn. D. 11,392, $396 \sim$ Nonn. $D$. 10,187, 192). Für alle drei Figuren, Ampelos, Kalamos und Karpos, wird ein Weiß-Rot-

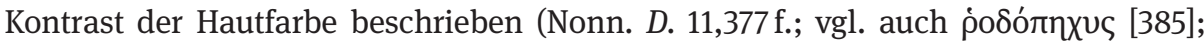

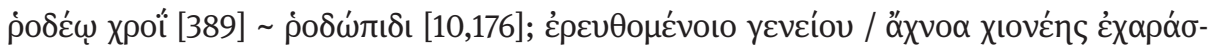

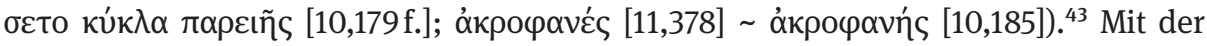
Analogie von Ampelos und Kalamos, die beide schon in ihrer menschlichen Gestalt Charakteristika der späteren Pflanze aufweisen (vgl. das Schilfrohr für Kalamos in

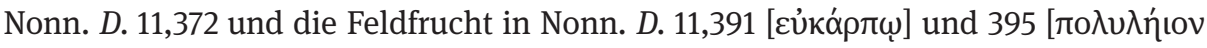
عủvńv]), ${ }^{44}$ spielt der Dichter mit den Möglichkeiten des Mythos. ${ }^{45}$

38 Vgl. D’Ippolito (1964) 137.

39 Hernández de la Fuente (2008) 41; García-Gasco (2011) 369.

40 Vgl. Gigli Piccardi (2003) 790f. Anm. ad 373-378. - Figurenporträts bietet Nonnos auch an anderen Stellen im Epos, siehe Kap. 3 Anm. 43.

41 Vgl. Vian (1995) 174 Anm. ad 341.

42 Vgl. Gigli Piccardi (1985) 59-63.

43 Vgl. Vian (1995) 176 Anm. ad 378; Gigli Piccardi (2003) 791 Anm. ad 373-378. - Die weiße

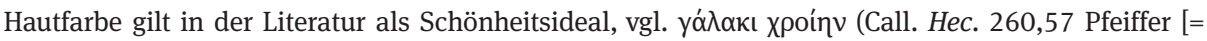

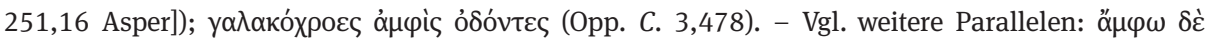

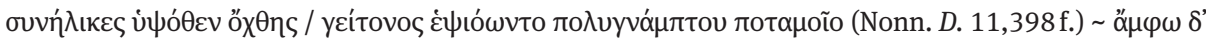

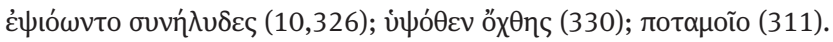

44 Im Gegensatz zum Satyrn wird die Metamorphose des Kalamos nicht ausgeführt; vgl. Gigli Piccardi (2003) 790 Anm. ad 372.

45 Vgl. Gigli Piccardi (2003) 793 Anm. ad 387-396. 
Der Katalog der mythischen Geliebten von Göttinnen in Nonn. D. 11,384-396,

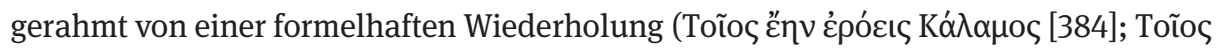

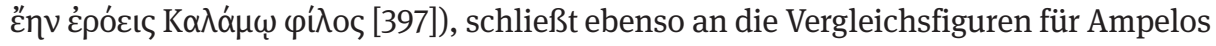
wie an das homerische Epos und hellenistische Dichtungsformen an: Orion (Nonn. $D$. 11,388, 390), Kephalos (390), Iasion und Endymion (392) erinnern an die hellenistischen Figuren Ganymed, Hylas und Hyakinthos, die dem Satyrn als Spiegelbilder

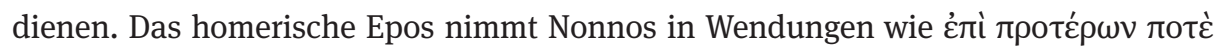

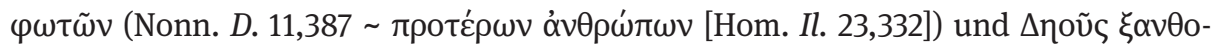

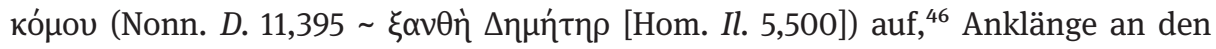
Hellenismus finden sich ferner in ausgewählten Lexemen und Wendungen: $\mu$ ṽ $\theta$ ov

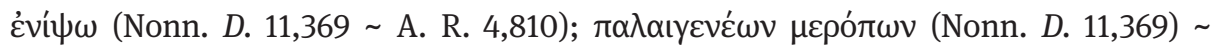

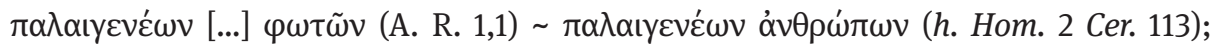

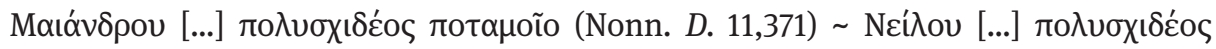

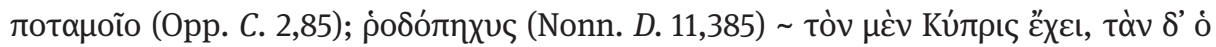

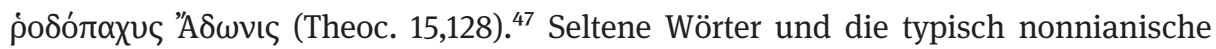

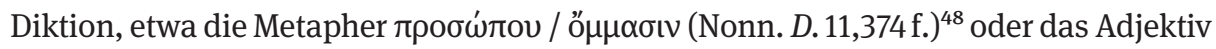

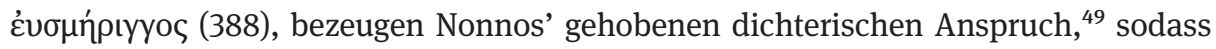
die Synkrisis zwischen Kalamos, Karpos und Ampelos im thematischen, strukturellen Bereich wie auf der lexikalischen Mikroebene realisiert wird.

Um die Erzählung des Kalamos-Karpos-Mythos mit der Ampelos-Episode weiter zu harmonisieren, führt er Wettspiele zwischen den beiden Knaben ein, die in einem Laufund einem Schwimmwettbewerb bestehen (Nonn. D. 11,400-426): ${ }^{50}$

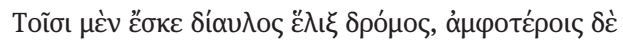

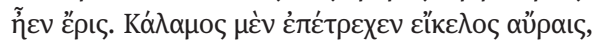

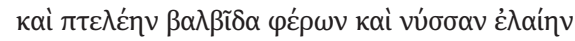

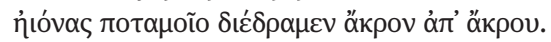

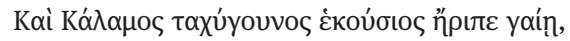

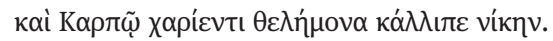

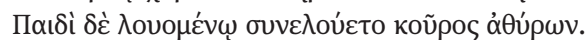

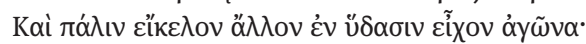

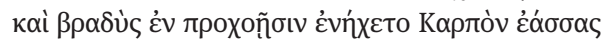

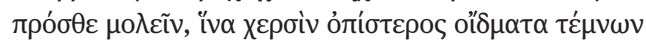

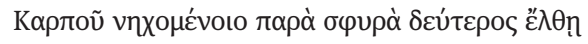

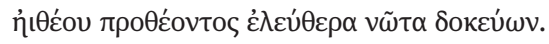

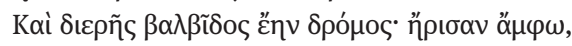

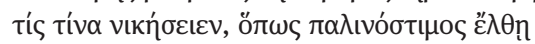

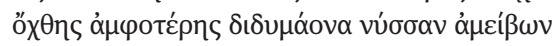
400 405

\footnotetext{
46 Vgl. Vian (1995) 176 Anm. ad 387 und 395; Gigli Piccardi (2003) 793 Anm. ad 387-396.

47 Vgl. Vian (1995) 173 Anm. ad 317, 176 Anm. ad 385.

48 Vgl. Gigli Piccardi (1985) 59-63; Vian (1995) 178 Anm. ad 374.

49 Vgl. Chuvin (1992) 140 Anm. ad 54; Vian (1990) 346 Anm. ad 255.

50 Vgl. Kröll (2013) sowie Mehl (1927) 39f. und Böhm (1948) 93 f., die auch eine deutsche Übersetzung der Schwimmszene bieten.
} 


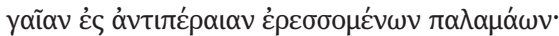

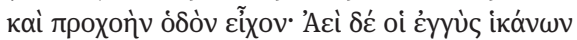

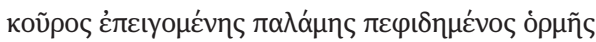

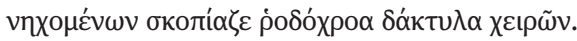

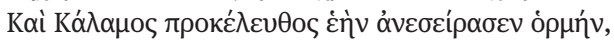

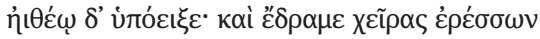

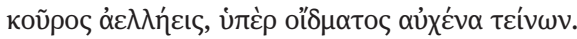

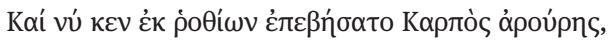

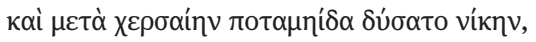

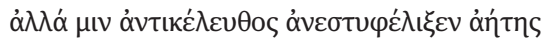

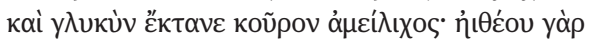

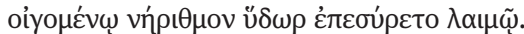

415

(400) Sie liefen die Rennstrecke doppelt um eine Wendemarke, und zwischen beiden war ein Wettstreit. Kalamos rannte den Winden gleich dahin und nahm als Startpunkt eine Ulme und als Ziel einen Olivenbaum; er lief das Flussufer entlang von einem Ende zum anderen. Und der knieschnelle Kalamos stürzte freiwillig auf die Erde (405) und überließ bereitwillig dem süßen Karpos den Sieg. Und zusammen mit dem badenden Knaben badete der Jüngling [sc. Kalamos] zum Vergnügen; und wieder hatten sie einen anderen, ähnlichen Wettkampf, diesmal im Wasser: Langsam schwamm er in den Fluten voran und ließ Karpos vorbeiziehen, um mit den Händen hinter ihm die Wogen durchschneidend (410) als Zweiter an die Knöchel des schwimmenden Karpos heranzukommen und den blanken Rücken des voranziehenden Jünglings betrachten zu können. Vom Start weg verlief die Bahn im Wasser. Beide kämpften darum, wer wen besiegen würde, wobei jeder wieder zurückkehren und zwischen den Ufern mit rudernden Händen (415) zum gegenüberliegenden Ufer eine doppelte Strecke mitsamt einer Wende zurücklegen musste. Im Wasser hielten sie ihre Bahn, und immer wieder kam der Jüngling [sc. Kalamos] nahe heran, aber er drosselte das Tempo seiner vorantreibenden Handbewegung und beobachtete die rosenfarbigen Finger der schwimmenden Hände [sc. des Karpos]. Und Kalamos, nach vorne ziehend, verlangsamte sein Tempo (420) und wich zurück vor dem Jüngling. Und der [sc. Karpos] eilte dahin, mit den Händen rudernd, der windschnelle Knabe, und streckte den Hals aus der Woge. Und da wäre Karpos aus den Wellen ans Land gestiegen und nach dem Sieg am Festland in einen Sieg zu Wasser eingetaucht; jedoch stieß ihn ein Gegenwind zurück (425) und tötete unerbittlich den süßen Knaben; denn in den geöffneten Mund des Jünglings strömte unmäßig viel Wasser.

Dem ausführlich geschilderten und am homerischen Epos orientierten Wettlauf im 10. Buch (Nonn. D. 10,383-412) setzt Nonnos denselben Wettbewerb, jedoch stark verkürzt entgegen, indem er in lediglich sechs Versen die summarische Zusammenfassung des Laufwettbewerbs zwischen Kalamos und Karpos mit demselben Ergebnis wie schon zuvor für Dionysos und Ampelos bietet (400 - 405). Die Bemerkung in Nonn. D. 11,406, dass die beiden Protagonisten nach dem Wettbewerb ein Bad im Fluss Maiandros nehmen, nimmt eine vergleichbare Situation aus Nonn. D. 10,380 - 382 wieder auf, wo Ampelos nach dem Ringkampf im Paktolos badet.

Mit der zweifachen Austragung der Schwimmwettbewerbe im 11. Buch der Dionysiaka verfolgt der Dichter bestimmte kompositorische Prinzipien und zieht, ähnlich wie zuvor im Porträt der beiden Knaben, thematische und lexikalische Verbindungslinien zur Ampelos-Episode: Das Schwimmen wird mit demselben Wortmaterial

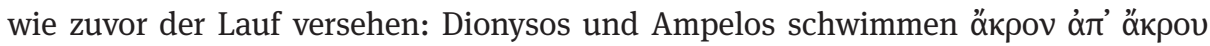

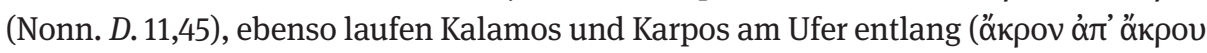


[403]). Nonnos übernimmt zudem den Wortschatz aus der typischen Szene Wettlauf, wendet diesen aber nicht nur auf den Laufwettbewerb, sondern auch in der neuen

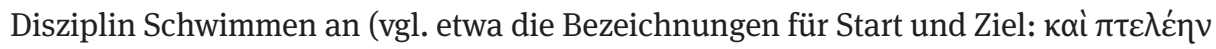

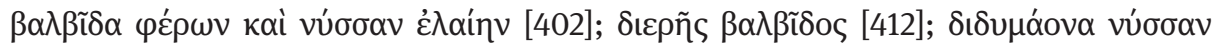

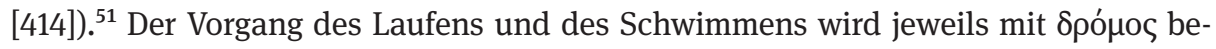

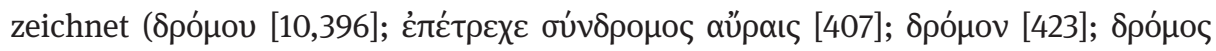

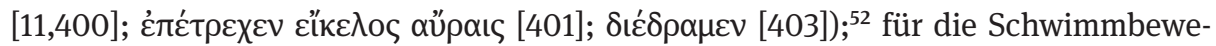

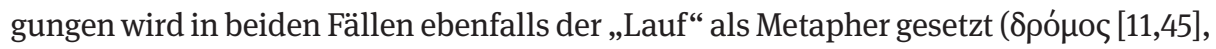

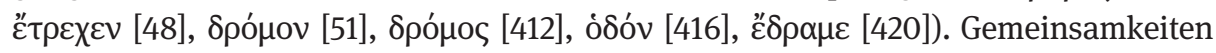
zwischen beiden Schwimmszenen können zudem für einzelne motivische Details konstatiert werden: Dionysos und Kalamos pflügen gleichsam durchs Wasser, ver-

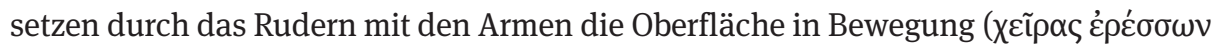

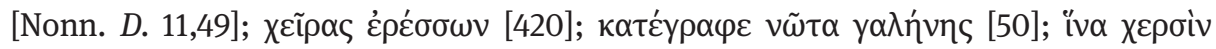
ó

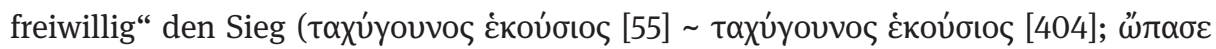

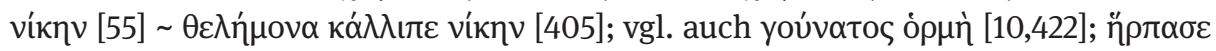
víkๆv [424]). Die Szenen sind zudem durch die Wiederaufnahme der folgenden Wörter

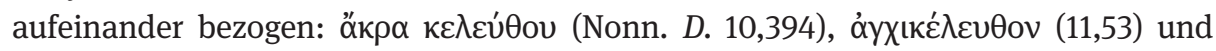

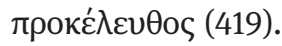

Neben wörtlichen Übereinstimmungen zur Ampelos-Episode bietet die KalamosKarpos-Erzählung auch Entsprechungen in der Komposition: Kalamos und Karpos erhalten vor Beginn der Wettspiele wie Ampelos ein ausführliches Porträt (Kalamos: Nonn. D. 11,370 - 384; Karpos: Nonn. D. 11,384-399; Ampelos: Nonn. D. 10,175-187). Die Ekphrasen schildern in allen Einzelheiten die körperlichen Vorzüge der jungen Männer, und zwar aus stets derselben Perspektive eines bewundernden Beobachters. Kalamos und Karpos ereilt dasselbe Schicksal wie Ampelos: Alle drei finden noch im Knabenalter den Tod, werden von ihren Nächsten betrauert, erleben eine Metamorphose in eine Kulturpflanze und sichern sich so einen festen Platz in der dionysischen Welt. Durch die Reprise des schon vom Beginn des 11. Buches bekannten Wettschwimmens gelingt es Nonnos, eine Verknüpfung zur Hauptlinie der Erzählung herzustellen. Mit der Technik der Doppelerzählung, in der sowohl Struktur als auch sprachliche Details miteinander abgeglichen werden, nimmt Nonnos vielleicht Anleihe bei traditionellen Genera wie dem homerischen Epos, der hellenistischen Dichtung oder dem antiken Roman..53 Das Außergewöhnliche der inhaltlichen Um-

51 Das Substantiv $\beta \alpha \lambda \beta$ ís bezeichnet ursprünglich die Startschwelle beim Laufwettbewerb, vgl. Jüthner u. Brein (1968) 52 - 54 mit Belegstellen; zum Einsatz von $\beta \alpha \lambda \beta$ íc in den Dionysiaka siehe auch Chrétien

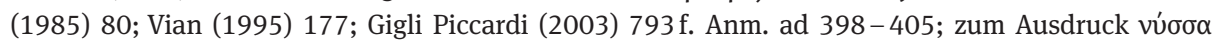
(„Rennbahn“) siehe Stegemann (1930) 30 Anm. 1 und Keydell (1931) 113 (145).

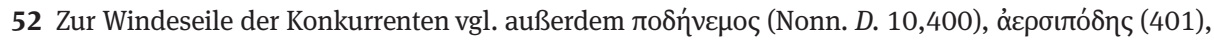

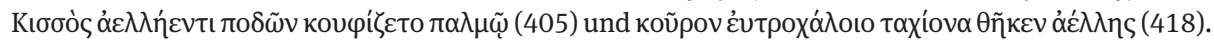
53 Vgl. Vian (1995) 19: „Le roman grec, héritier de l’Odyssée, aime la narration, à tiroirs‘, avec des récits secondaires enchâssés dans la narration principale. Nonnos se plaît lui aussi à introduire des 
setzung und das besondere Augenmerk auf die Form sind der Wesenskern nonnianischer Dichtung: „L'essentiel n'est plus le contenu de l'histoire ou de l'episode, c'est la façon dont elle est narrée, dont les elements du texte entier sont mis en relation les uns avec les autres.“54

Mit der Erzählung um Kalamos und Karpos greift der Dichter auch auf künftige Ereignisse in der Ampelos-Episode vor, insbesondere wenn er einen Ausblick auf die Motive der Wiedergeburt und der Metamorphose in eine Pflanze gewährt: Der sich in Schilfrohr verwandelnde Kalamos und Karpos, die Personifikation der Feldfrucht, ziehen zu Ampelos, dem Weinstock, eine direkte Linie..$^{55}$ Die ansonsten nirgendwo belegte Episode um Dionysos und Ampelos, die überdies mit einem der epischen Tradition fremden Schwimmwettbewerb versehen wird, erfährt durch die motivische Wiederaufnahme in der Kalamos-Karpos-Erzählung ihre mythische Beglaubigung. Die in der Chronologie des nonnianischen Mythengebäudes vorher eingereihte KalamosKarpos-Erzählung wird zur mise-en-abîme ${ }^{56}$ für Ampelos' Schicksal und legitimiert dieses durch die Autorität eines älteren Mythos.

\subsection{Kosmologie als Ordnungsprinzip - die Horen, Helios, Zeus und Aion}

Die Verankerung in einer eigens für dieses Epos geschaffenen mythischen Tradition wird zusätzlich durch Eros, den Erzähler der Kalamos-Karpos-Episode, getragen. ${ }^{57}$ Der Liebesgott ist für Nonnos die erste Gottheit überhaupt, die im neuen, dionysischen Zeitalter das Licht der Welt erblickt. Der Beginn dieser neuen Ära wird am Ende des 6. Buches durch die Säuberung der Welt mittels der von Zeus geschickten Sintflut vorbereitet (Nonn. D. 6,229-388) und am Beginn des 7. Buches durch die schöpferische Kraft des Eros eingeläutet (7,1-3). Die zu einem kosmologischen Prinzip gewordene

epyllia à l'intérieur de son epopée: c'est le cas pour l'histoire de Calamos et de Carpos.“ Vgl. Collart (1930) 99; Duc (1990) 183 weist auf eine vergleichbare Situation in Call. Lav. Pall. hin; dort findet sich mit der Geschichte des Teiresias, der, da er die Göttin unbekleidet beobachtet hat, mit Blindheit geschlagen wird, ein zur Kalamos-Karpos-Episode analoger Einschub, zudem wird die Geschichte von Aktaion und Artemis eingefügt. Beide, Teiresias und Aktaion, rücken durch Motivparallelen eng aneinander. Zur Technik der Digression in der hellenistischen Literatur vgl. auch Heath (1989) $59-67$. 54 Duc (1990) $185 \mathrm{f}$.

55 Gigli Piccardi (2003) 734 weist auf die Wichtigkeit hin, die das Schilf für die Ampelos-Handlung haben wird; Schilf gehört, wie aus kaiserzeitlichen Papyri ersichtlich ist, in der antiken Landwirtschaft ebenso zur Weinkultur wie andere Gewächse, die dem Wein als Stütze dienen.

56 Zur Definition von mise-en-abîme siehe Dällenbach (1977).

57 Zur Eros-Figur in der Ampelos-Episode vgl. S. 67, 80 und 85; zur Funktion des Eros in den Dionysiaka siehe auch Stegemann (1930) 25 f. - Der Gott Eros lässt sich auch mit neuplatonischer Kosmologie in Verbindung bringen, vgl. Bargeliotes (2002) 14: „[...] Eros, the love of the artist, is known to be the oldest divine artist, transforming chaos into kosmos. The blessed and happy kosmos is, therefore, the outcome of love for a balanced and harmonious achievement.“ 
Autorität des Eros verleiht der Geschichte zusätzlich an Glaubhaftigkeit und stellt die Entwicklungen um Dionysos und Ampelos in einen größeren mythisch-evolutionären Kontext. Die Etablierung des dionysischen Kultes, der kultischen Attribute und des Kultpersonals sowie die letztliche Anerkennung des Dionysos sind allesamt Teil dieser Evolution. Umgekehrt nimmt auch Eros von Anfang an einen festen Platz in der neuen dionysischen Welt ein, wenn die Macht der Liebe am Ende des 12. Buches im Rahmen des ersten dionysischen Komos der Satyrn und Nymphen als Konsequenz des übermäßigen Weingenusses sichtbar wird; Weinstock, Wein und Liebe sind hier fest miteinander verbunden und müssen in einem Atemzug mit Dionysos genannt werden.

Eros, der sich auf einer den Geschehnissen um Ampelos übergeordneten Ebene befindet, bringt zudem einen kosmologischen Aspekt ein, der als ein charakteristisches Stilmerkmal spätantiker Literatur sogar die narrative Leitlinie von Dichtung, wie etwa im Falle der Ekphrasis des Kosmos bei Johannes von Gaza, bestimmen oder aber in einen größeren narrativen Kontext eingefügt werden und der Strukturierung, Kommentierung oder Reflexion dienen kann. ${ }^{58}$ Die Ampelos-Episode bietet - neben der Eros-Figur - mit der Konsultierung der Tafeln der Harmonia durch die Horen eine kosmologische Szene, die für die Komposition der Geschichte um den jungen Satyrn bestimmend ist. Die Tafeln, Repräsentanten göttlicher Ordnung und Harmonie, die den Menschen durch den Wein garantiert wird, ${ }^{59}$ sind mit Göttern und Personifikationen göttlich-schicksalshafter und für den Lauf der Zeiten verantwortlicher Prinzipien verbunden, durch welche die Ampelos-Episode eine Beglaubigung von höchster Instanz her erfährt. Indem die Episode den ihr zugedachten Platz in der Chronologie des Weltenkosmos erlangt, wird sie als in sich schlüssig, ihr Ausgang als folgerichtig definiert. ${ }^{60}$

Auch außerhalb der Bücher 10-12 finden sich kosmologische Szenen, die der Verankerung der Ampelos-Episode in einem breiteren narrativen Kontext dienen und weit auseinanderliegende Teile der Dionysiaka in Relation zueinander setzen. An mehreren Textstellen konsultieren Gottheiten mit einem sehr persönlichen Anliegen eine andere göttliche Instanz: So erstellt etwa im 6. Buch Astraios auf Anfrage der Demeter ein Horoskop für deren Tochter Persephone, in welchem er die Verbindung Persephones mit Zeus und die Geburt des gemeinsamen Sohnes Zagreus, des ersten Dionysos, prophezeit (Nonn. D. 6,1-108). ${ }^{61}$ Sodann sucht im 7. Buch Aion Zeus auf, um

58 Zur Kosmologie in den Dionysiaka vgl. Fauth (1981) 158-179. - Auch Claudian unterstreicht im zweiten Gedicht auf den Konsulat Stilichos dessen Tugenden durch die Einbeziehung kosmologischer Prinzipien, vgl. Müller G. M. (2011) 315-317.

59 Vgl. Hernández de la Fuente (2008) 77. - Der Kampf zwischen Ordnung und Chaos ist ein wesentliches Element der Poetik der Dionysiaka und findet sich bereits in der Auseinandersetzung zwischen Zeus und Kadmos mit dem Usurpator Typhon (Nonn. D. 1,137 - 320; 2,1 - 712), vgl. Vian (1988) 286f. (433f.); Hernández de la Fuente (2008) 65 - 78.

60 Zur Personifikation von kosmischen Prinzipien und Göttern der Zeit vgl. Miguélez Cavero (2013) $352-359$.

61 Vgl. Chuvin (1992) 5-12; Liebeschuetz (1996) 81. 
Informationen über die Zukunft des Menschengeschlechts einzuholen, und erhält die Prophezeiung, dass es mit der unmittelbar bevorstehenden Geburt des Dionysos Rettung für die Menschheit geben werde (Nonn. D. 7,1-109). Ein göttlicher Besuch erfolgt schließlich im 41. Buch mit der Befragung Harmonias durch Aphrodite (Nonn. D. 41,273-398); ${ }^{62}$ Gegenstand der Sorge ist Beroe, nach der Version bei Nonnos Tochter der Aphrodite und des Adonis (Nonn. D. 41,155-157), deren Bedeutung für Rom als juristische und zivilisatorische Macht auf sieben prophetischen Tafeln angekündigt wird, die eine direkte Linie zum 12. Buch ziehen. ${ }^{63}$

Die Horen-Episode selbst dient nicht nur dazu, die Geschichte um Ampelos in einen breiteren Kontext einzuordnen, sondern auch als narrative Klammer und Kompositionsprinzip. Die an zentralen Passagen des Epos auftauchenden Horen werden erstmals im Rahmen der Typhonomachie im 1. Buch als Repräsentantinnen

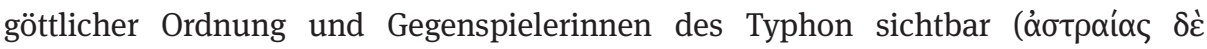

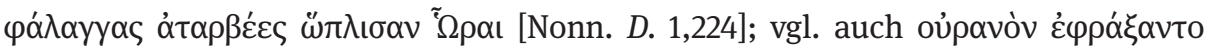
$\varphi$ als Hüterinnen der Tore zum Olymp den siegreichen Zeus an seinem angestammten

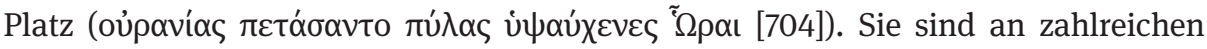
Stellen nach der Ampelos-Episode Sinnbild des geordneten Kosmos. ${ }^{64}$

Da die Ankündigung des Weines durch die Horen am Ende des 11. und Beginn des 12. Buches eine Schlüsselpassage des Epos ist, wird sie erzähltechnisch über mehrere Bücher hinweg sorgfältig vorbereitet: In ihrer Funktion als Prophetinnen des neuen, dionysischen Zeitalters sind die Horen bereits in der Szene mit dem Bad Semeles

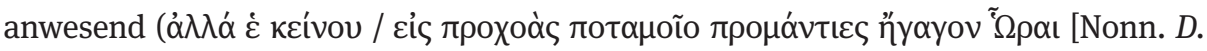
7,178f.]). Ähnlich wie sie am Beginn der Ampelos-Episode Dionysos bei seiner ersten

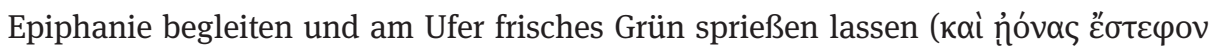

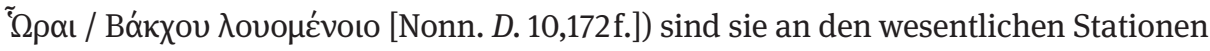
bis zur Geburt des Dionysos stete Begleiter von Zeus und Semele (nach ihrer Liebes-

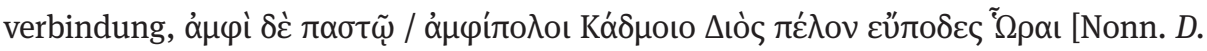

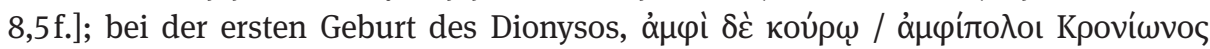

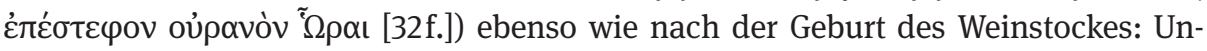
mittelbar bevor sich der Heereszug gegen die Inder in Bewegung setzt, wird dem

62 Vgl. Liebeschuetz (1996) 81; Chuvin u. Fayant (2006) 19-27; Hernández de la Fuente (2008) 78. 63 Zur Beroe-Episode vgl. Bajoni (2003); Hernández de la Fuente (2008) 109-116; zu den Tafeln der Harmonia in Buch 41 und zur typisch nonnianischen Szene der Konsultierung einer höheren göttlichen Instanz siehe Vian (1993).

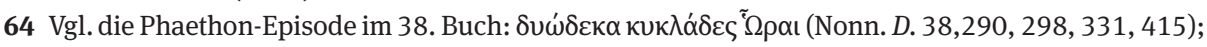
außerdem sind die Göttinnen der Jahreszeiten maßgebliche Faktoren der Chronologie des Indien-Zuges

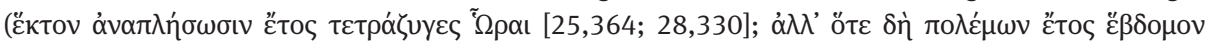

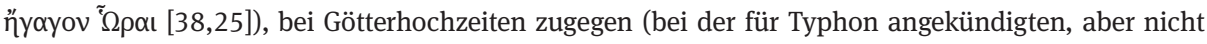
ausgeführten [2,328]; bei Helios und Klymene [38,131]) sowie bei der Geburt von göttlichen Kindern (Emathion [3,381]; Telete, der Tochter des Dionysos und der Nikaia [16,397]; Beroe [41,184]; der Zwillinge Auras $[48,801])$ und werden regelmäßig als Herrscherinnen über die Vegetation dargestellt:

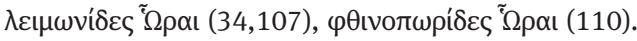


nunmehr mit sämtlichen Attributen ausgestatteten Dionysos die Aufnahme in den

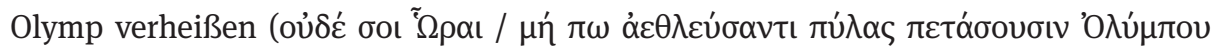
[Nonn. D. 13,23f.]), über dessen Tore die Horen wachen und durch die sie Zeus und seinem Sohn Dionysos schließlich den Zugang gewähren. Die Horen werden Teil der dionysischen Sphäre, wenn sie beim Gelage im Palast des Staphylos zusammen mit

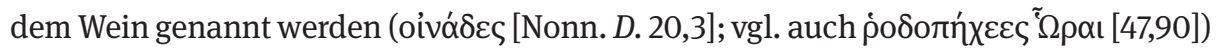

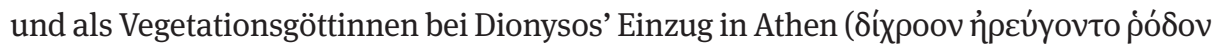

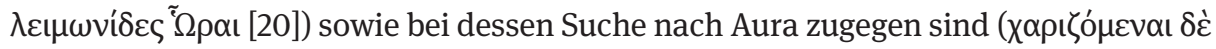

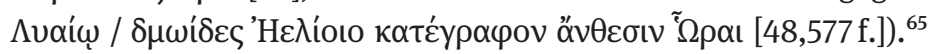

Die Erzähllinie mit Dionysos und den Horen findet in der Ampelos-Episode ihren Höhepunkt, wenn sie Dionysos von seiner Epiphanie bis zur Genese seines Hauptattributs als Vegetationsgöttinnen begleiten und immer dann anwesend sind, wenn dieser an einen für seine Entwicklung wichtigen Wendepunkt gelangt. Die kompositionsbildende Funktion der Horen zeigt sich insbesondere darin, dass Nonnos ihren Auftritt in der Ampelos-Episode schon in vorangehenden Büchern vorbereitet, indem er sie schon im 9. Buch den soeben zum zweiten Mal geborenen Dionysos mit einem Efeu-Schlangen-Kranz krönen lässt (Nonn. D. 9,11-15):

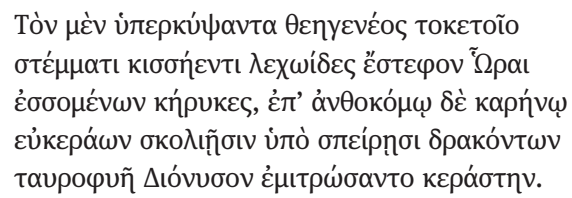

Ihn, der gerade den Kopf von der gottgegebenen Geburt hob, bekränzten die Horen als Geburtshelferinnen, die Botinnen der Zukunft, mit einem Efeukranz. Und auf sein blumenbedecktes Haupt setzten sie ein gewundenes Band von schöngehörnten Schlangen, (15) ihm, dem Stiergestaltigen, dem gehörnten Dionysos, als Kranz.

Die durch die Horen vollzogene Krönung mit dem Efeukranz, die Dionysos' Funktionsbereiche als Wein- und Vegetationsgott vorwegnimmt, ${ }^{66}$ zeigt die Göttinnen auch als Repräsentantinnen der zyklisch ablaufenden, Wachstum und Gedeihen bestimmenden Zeit. Ihre doppelte Anwesenheit, bei der Geburt des Gottes und der Genese des Weines, bindet sie über Buch- und Episodengrenzen hinweg durch das Vegetationsmotiv eng an Dionysos. ${ }^{67}$ Auch in der Vorbereitung auf den Wein spielen die Jahreszeiten eine tragende Rolle, indem sie in der Szene um Zeus und Aion zu Beginn des 7.

65 Mit der Bezeichnung der Horen als „Dienerinnen des Helios“ in Nonn. D. 48,577 f. wird ihr Besuch im Palast des Sonnengottes zu Beginn des 12. Buches in Erinnerung gerufen; vgl. auch $\tau \alpha \rho \beta \alpha \lambda \varepsilon$ เ

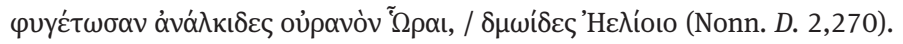

66 Vgl. Gigli Piccardi (2003) $636 \mathrm{f}$.

67 Vgl. Stegemann (1930) 126; Gigli Piccardi (2003) 739, 803; Hernández de la Fuente (2008) 77, 85. Für Duc (1990) 186 zeigt sich anhand der Horen-Episode: „[...] tout est bel et bien planifié.“ 
Buches das Kommen der neuen Pflanze aus deren Nicht-Existenz heraus motivieren (Nonn. D. 7,7-21): ${ }^{68}$

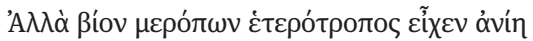

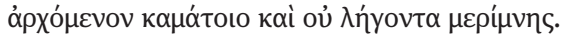

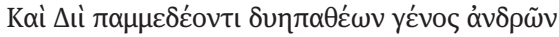

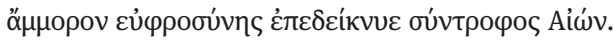

Ov̈ $\pi \omega$ yà

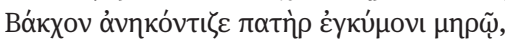

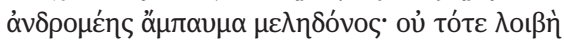

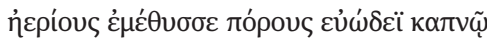

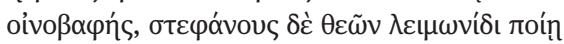

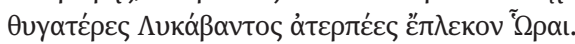

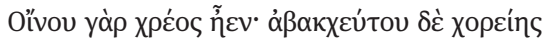

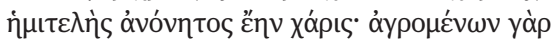

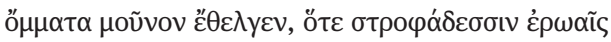

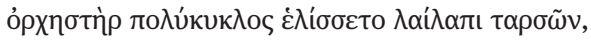

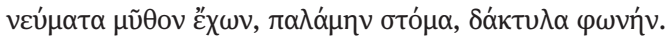

\begin{abstract}
Aber das Leben der Menschen hatte einen andersartigen Kummer, denn es begann mit Plage und hatte kein Ende der Sorge. Und dem Zeus, dem Allherrscher, zeigte das Geschlecht der Menschen, welches Mühsal erdulden musste und (10) ohne Freude war, sein Bruder Aion. Denn noch nicht hatte der Vater die Fäden der Geburt gelöst und Bakchos im schwangeren Schenkel hervorschießen lassen, ihn, als Ende des menschlichen Leids. Noch nicht hatte damals die Trankspende die luftigen Bahnen berauscht mit ihrem wohlriechenden Dampf, (15) die weinschwere; und Kränze aus Wiesengras für die Götter flochten freudlos die Horen, die Töchter des Jahres. Denn an Wein fehlte es. Und beim Tanz ohne Bakchos herrschte nur halbe und unergiebige Freude. Denn nur die Augen der Teilnehmer bezauberte er, wenn durch rasche Drehungen (20) ein Tänzer in vielen Kreisbewegungen sich im Wirbel der Füße drehte und das Nicken als Rede, die Hand als Mund, die Finger als Stimme hatte.
\end{abstract}

Am Beginn der dionysischen Ära wird der Mangel an Dionysischem konstatiert, indem - ähnlich der Ekphrasis des Herbstes im 11. Buch - durch die Häufung von Negationen besondere rhetorische Eindringlichkeit erreicht wird: „Noch nicht“ (Oü $\pi \omega$ [Nonn. $D$. 7,11]) ist Dionysos auf wundersame Weise aus dem Schenkel des Zeus geboren, „noch

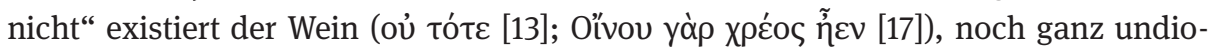

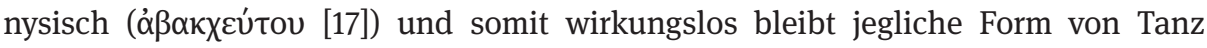

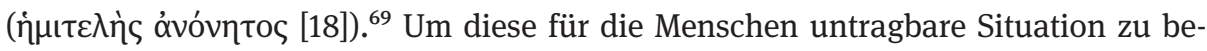
seitigen, richtet Aion das Wort an Zeus (Nonn. D. 7,29-66), der die Geburt des Dionysos und die Entstehung des Weines vorankündigt $(73-105)^{70}$ und so die Metamorphose des Ampelos vorwegnimmt. Der Dichter begründet die kommende Episode durch

68 Zur Szene vgl. Stegemann (1930) 100-107; Spanoudakis (2012).

69 Das rhetorische Stilelement der gehäuften Negationen steht sowohl im 7. als auch im 11. Buch für die kosmologische Tragweite des Geschehens, vgl. Gigli Piccardi (2003) 526f., $807 \mathrm{f}$.

70 Für Text und Übersetzung der Stelle siehe S. 58f. 
rhetorische Argumentationsführung und schafft eine direkte Verbindung zum Auftritt der Horen im 11. und 12. Buch. ${ }^{71}$

Auch Aion selbst wird zu einer kompositorischen Konstante in den Dionysiaka, ${ }^{72}$ wenn er im 3. Buch Kadmos das Wort an seine Gastgeberin Elektra, seine zukünftige Schwiegermutter, richten und über die zyklische Wiederkehr von Leben und Tod philosophieren lässt (Nonn. D. 3,248-256): ${ }^{73}$

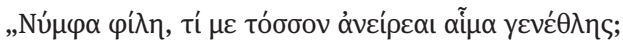

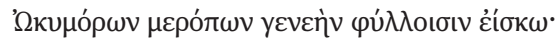

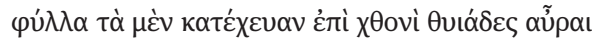

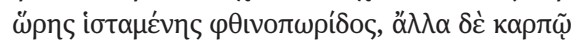

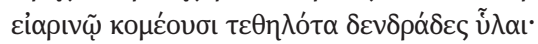

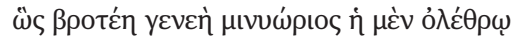

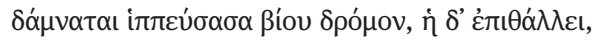

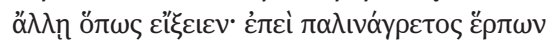

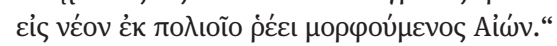

\begin{abstract}
„Liebe Frau, was fragst du mich so viel nach dem Blut meiner Abstammung? Das Geschlecht der früh sterbenden Menschen vergleiche ich mit Blättern: (250) Die rasenden Winde schütteln die Blätter auf die Erde, wenn die Herbstzeit zu Ende geht, aber von frühlingshafter Frucht lassen die baumreichen Wälder ihre Blätter wieder sprießen. So kurzlebig ist das sterbliche Geschlecht; die einen werden durch die Vergänglichkeit bezwungen, wenn sie den Lauf des Lebens dahingeeilt sind, die anderen aber blühen auf, (255) um wieder anderen zu weichen. Denn Aion kriecht wieder zurück zum Anfang und fließt, von einem Grauhaarigen zu einem Jungen verwandelt, wieder zurück.“
\end{abstract}

Die „kosmische Mythologie“74 von hierarchisch geordneten göttlichen Mächten, die für den chronologischen Lauf und die Harmonie des Universums verantwortlich sind,

\footnotetext{
71 Vgl. Kuhlmann (1999) 405; Hernández de la Fuente (2008) 65, 76. Zur Kompositionslinie zwischen den Szenen im 7. Buch und dem Auftritt der Horen in der Ampelos-Episode siehe Chuvin (1991) 196; auch Dupuis (1847) 130 sieht die Anordnung der 48 Bücher nach den vier Jahreszeiten als ein Kompositionsprinzip der Dionysiaka an; vgl. Stegemann (1930) 100-172.

72 Vgl. Stegemann (1930) $26 \mathrm{f}$.

73 Nonnos knüpft an dieser Stelle auch an literarische Topoi an: Der Vergleich des kurzen Menschenlebens mit dem Fallen der Blätter zur Herbstzeit ist aus Homer und Mimnermos bekannt, wobei

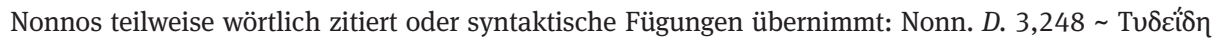

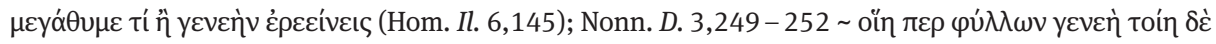

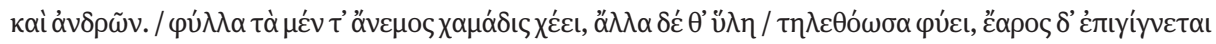

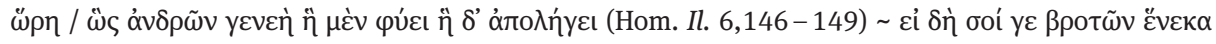

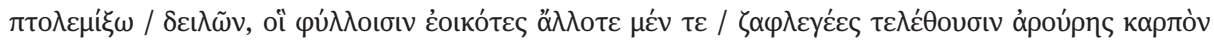

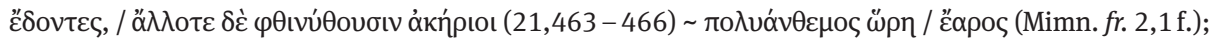

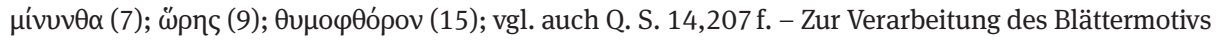
in Homer und Nonnos vgl. Bannert u. Kröll (2016).
}

74 Keydell (1961) 112 (530). 
lässt sich mit philosophischen Gedankengebäuden wie dem Neuplatonismus verbinden. ${ }^{75}$

Mit der Einfügung Aions, der Horen und des Helios in die Dionysiaka schafft Nonnos nichts genuin Neues, sondern greift auf Tendenzen der spätantiken Literatur und Kunst zurück. ${ }^{76}$ Literarische Folien für die Horen finden sich bereits in den homerischen Epen, wo sie als Wächterinnen des Tores zum Olymp (Hom. Il. 5,749; 8,393) und der heiligen Pferde Heras und Athenes auftreten (Hom. Il. 8,433). Für die Dichter der archaischen, klassischen und hellenistischen Zeit sind sie Symbol für die blühende Vegetation und das Leben und können bei bedeutenden Ereignissen wie der Geburt einer Gottheit oder auch an Wendepunkten des menschlichen Lebens anwesend sein; bei Pindar kümmern sich die Horen und die Erdgöttin Ge um den soeben geborenen Aristaios (Pi. P. 9,59-61), und bei Philostrat helfen sie bei der Geburt des Hermes (Philostr. Im. 1,26). Bei Simonides von Keos (6./5. Jh. v. Chr.) und bei Athenaios rücken Dionysos und die Horen durch ihre Zuständigkeitsbereiche Vegetation und Erneuerung der Natur eng zusammen ( $\alpha$ i $\Delta$ เovvoí $\alpha \delta \varepsilon \varsigma$ [Simon. fr. 146 Bergk = AP 13,28; Ath. II,3 Kaibel S. 84,7-11]). ${ }^{77}$ Zudem können die Horen Begleiterinnen mythischer Hochzeiten sein wie etwa bei der von Peleus und Thetis oder bei der von Dionysos und Ariadne (Horae rosis et ceteris floribus purpurabant omnia [Apul. met. 6,24]), und spätestens im Hellenismus werden sie unter dem Einfluss philosophischer Strömungen ins kosmologische System mit Helios an der Spitze eingeordnet. ${ }^{78}$

Eine literarische Auseinandersetzung mit den Horen lässt sich auch für die Kaiserzeit feststellen: ${ }^{79}$ Im Epitaphios auf seinen verstorbenen Sohn Rufinus vergleicht Himerios den frischen Bartflaum des noch jungen Dionysos mit einer Frühlingsblume:

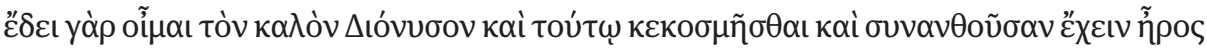

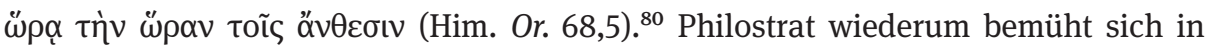
seinen Imagines um eine getreue Wiedergabe der ikonographischen Tradition, wenn er die Herbsthore mit ihrem charakteristischen Attribut, der Weinrebe, versieht: $\chi \alpha \rho i ́ \varepsilon v$

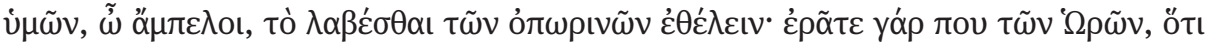

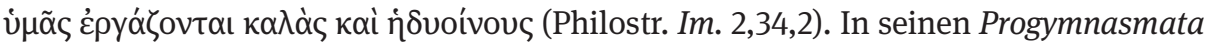

75 Vgl. schon Ouwaroff (1817) 22. - Zu Nonnos und dem Neuplatonismus vgl. Hernández de la Fuente (2011a); Hernández de la Fuente (2014).

76 Vgl. Stegemann (1930) 130-132 Anm. 8, 133 f. Anm. 13, 134f. Anm. 15, 136 f. Anm. 19.

77 Vgl. Hanfmann (1951) 82, 95, 258; siehe auch Dunbabin (1978) 186: „Just as the Seasons in most of their appearances on mosaics seem principally to evoke a general, predominantly material, state of fertility and prosperity, so Dionysus when he accompanies them is thought of primarily [...] as the god of wine and of fruitfulness and vegetation in general“; vgl. auch Merkelbach (1988) 7. - Zur Verbindung von Dionysos und den Horen vgl. auch AP 13,28 und Gigli Piccardi (2003) $636 \mathrm{f}$.

78 Vgl. Hanfmann (1951) 104-111.

79 Vgl. Vian (1995) 26 Anm. 2, 3, 4; Gigli Piccardi (2003) 636f., 739.

80 Ein ähnliches Weltbild wie hier bei Nonnos wird im darauffolgenden Paragraphen der HimeriosRede geboten, wo der große Weise den Ablauf der Jahreszeiten festsetzt, also auch den Herbst definiert (Him. Or. 68,6); vgl. auch Claud. Stil. 2,424-476. - Zu Him. Or. 68 vgl. Kennedy (1983) 146. Zum Horen-Motiv bei Himerios siehe auch die Hochzeitsrede Him. Or. 9,19. 
illustriert Libanios das Erwachen der Natur und den Neubeginn menschlichen Lebens in einer ekphrastischen Charakteristik des Frühlings (Lib. Prog. 12,7 Gibson) ${ }^{81}$ Auch die spätantike und byzantinische Kleindichtung verarbeitet mit Vorliebe diesen Stoff, so charakterisiert etwa Johannes von Gaza in seiner Beschreibung der Tabula mundi in nonnianischer Diktion die Herbsthore (Jo. Gaz. 2,283-296), ${ }^{82}$ und auch in den Gedichten Nr. 4 und 5 des Johannes Geometres (10. Jh.) sind sämtliche Elemente der Natur- und Vegetationstopik in der Ekphrasis des Frühlings vereint. ${ }^{83}$

Nonnos knüpft auch an spätantike ikonographische Traditionen an, die besonders in der Sarkophag- und der Mosaik-Kunst zu den gängigen Ausdrucksformen gehören. ${ }^{84}$ Großer Beliebtheit erfreuen sich die Horen auf kaiserzeitlichen Mosaiken ab dem 2. Jh. n. Chr., die im ganzen römischen Reich zu finden sind. ${ }^{85}$ Als Beispiel für die Vielzahl an Darstellungen sei ein Mosaikboden aus einem Privathaus in El Djem in Tunesien genannt, der den Genius des Jahres in Verbindung mit den vier Jahreszeiten zeigt: ${ }^{86}$ Der Personifikation des Jahres in einem zentralen Medaillon ist je eine Hore, ausgestattet mit ihrem persönlichen Attribut, in einer der vier Ecken gegenübergestellt. „Aion, der bei Nonnos so stark hervortritt“ ${ }^{87}$ ist in der Ikonographie der Sarkophage und Mosaiken ein gängiger Begleiter der Horen, ${ }^{88}$ ein prominentes Beispiel hierfür ist das sog. Haus des Aion in Nea Paphos auf Zypern, in dem nicht nur kaiserzeitliche Mosaiken mit Personifikationen des Kosmos - Aion, Helios, Selene -, sondern auch ein Bildzyklus mit dionysischen Themen, darunter ein Triumphzug des Dionysos, gefunden wurden. ${ }^{89}$ Auf einem Sarkophag aus der Villa Carpegna in Rom, welcher zudem eine

81 Vgl. Gibson (2008) $442-445$.

82 Vgl. auch Gigli Piccardi (2003) 804, 806.

83 Vgl. Ciccolella (2000) 143-159. Ciccolella setzt die Gedichte in Verbindung zu heidnischen Frühlingsfesten, an denen zugleich der Geburtstag des Kaisers gefeiert wurde; derartige Festlichkeiten waren bis zur Ausbreitung des Christentums in allen Teilen des römischen Reiches populär.

84 Vgl.Turcan (1966) 593-625; Koch u. Sichtermann (1982) 218, 222 mit weiteren Literaturangaben; Parrish (1984). In der spätantiken Ikonographie werden die Jahreszeiten oftmals in dionysischem Kontext zusammen mit dem Weingott gezeigt.

85 Vgl. Hanfmann (1951) 231; Foucher (1963) 134-136.

86 Vgl. Foucher (1963) 35-42, 57-61, mit Abbildungen.

87 Schmid u. Stählin $\left(1980 /{ }^{6} 1924\right) 968$.

88 Vgl. Hanfmann (1951) 230, 258 sowie den Artikel „Aion“ in LIMC I/1, 399-411 mit einer Zusammenstellung der ikonographischen Typen. Als weiteres Beispiel für eine Darstellung Aions seien die Mosaiken aus einem Mithräum im spanischen Mérida genannt, die neben Aion auch andere Personifikationen abstrakter Begriffe zeigen, vgl. Blázquez (1993) 148-150, 381; siehe auch die Darstellungen in Parrish (1995); Dunbabin (1999) 123 Abb. 126 und 168 Abb. 174; zu Aion in der spätantiken Kunst und Literatur vgl. Zuntz (1991) und Zuntz (1992).

89 Vgl. Daszewski (1965) 13f., 16-21, 38 -45; Liebeschuetz (2001) 226-229. - Vgl. auch Giannoulis (2010) 68f., der ein spätantikes Mosaik aus Philippopolis/Plovdiv anführt, das neben Prometheus mit einem menschlichen Geschöpf aus Ton auch Ge und Aion zeigt; Thema der Darstellung ist der zyklische Wechsel von Werden und Vergehen der Natur. 
Szene mit dem Triumphzug des Dionysos bietet, findet sich die früheste bekannte Jahreszeiten-Darstellung der Sarkophagkunst. ${ }^{90}$

In der bildenden Kunst und Literatur der Spätantike, also auch in den Dionysiaka, kommt den Horen, Helios, Zeus und Aion weniger eine heidnisch-religiöse Wertigkeit als vielmehr die Funktion der Repräsentanz einer paganen Tradition zu, die in der enzyklopädischen Gelehrsamkeit des spätantiken Ägypten lebendig geblieben ist. Dass sie zu religiös neutralen Gestalten, zu allgemeingültigen Faktoren innerhalb der kosmischen Weltordnung geworden sind, ergibt sich auch aus ihren Auftritten in der Paraphrase. ${ }^{91}$ In beiden Epen reflektiert Nonnos künstlerische Traditionen, indem er die Horen, Helios, Zeus und Aion als Exponenten der periodisch sich erneuernden Welt einsetzt, die den gleichfalls göttlichen Status des jeweiligen Protagonisten untermauern sollen. Es gelingt ihm, zwischen den Büchern 6, 7,11 und 12 der Dionysiaka durch die wiederkehrenden Figuren sowie durch die typische Szene der Konsultation einer höheren, göttlichen Instanz kompositionelle Verbindungslinien $\mathrm{zu}$ schaffen, innerhalb derer sich die Metamorphose des Ampelos vollzieht. Weit davon entfernt, eine bloß sekundäre Zutat zu sein, verbindet die Horen-Szene des 11. und 12. Buches die Prophezeiung des Zeus und die Schenkel-Geburt des Dionysos mit der ersten Epiphanie des Gottes und der Ankündigung der Genese des Weines, sodass sie zur wichtigen Scharnierstelle und zum Siegel nonnianischen Dichtens wird.

\subsection{Dionysischer Kult}

Maßgebliche Komponenten der narrativen Struktur bilden die zahlreich in der Episode anzutreffenden dionysischen Kultelemente, zum einen Motivparallelen und Themenwiederholungen, zum anderen einzelne typische Kultgegenstände, mittels derer Nonnos auf das Ziel der Erzählung, die Etablierung des Dionysos als Gott, hinarbeitet. ${ }^{92}$ Anhand der Ampelos-Figur thematisiert der Dichter zunächst die Praxis dionysischer Ausdrucksformen im Bereich Musik und Tanz: Von Beginn der Episode an frönt

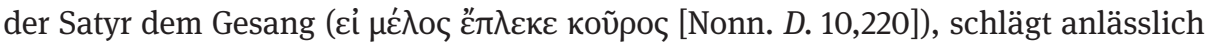

90 Vgl. Hanfmann (1951) 22. - In der Sepulkralkunst genießt auch die Abbildung der Weinernte Popularität, die von Anhängern des Dionysos begleitet von Gesang und Tanz durchgeführt wird; vgl. Zanker u. Ewald (2004) 153, 156f. Abb. 141.

91 Aion in der Paraphrase: Nonn. P. 1,191; 3,79; 6,147, 179; 8,94, 157; 9,9, 154; 10,102; 11,87;

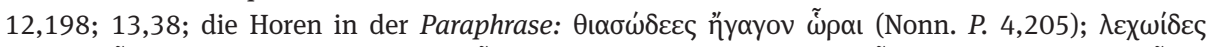

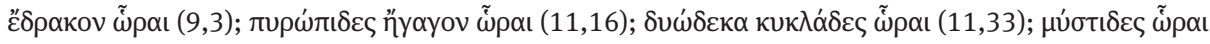
(12,6); vgl. Golega (1930) 63 - 65; Thraede (1962) 1002f. sowie auch Bogner (1934) 333, der trotz seiner einseitigen Interpretation der beiden nonnianischen Epen - die Dionysiaka werden als rein heidnisch bewertet, die Paraphrase als christlich - einige Figuren, darunter Hades, Aion und die Horen, als bloße literarische Figuren ohne religiöse Konnotation ansieht.

92 In der Szene um Dionysos und seine Amme Mystis in Nonn. D. 9,111-131 werden ebenfalls dionysische Kultinstrumente vorweggenommen, vgl. García-Gasco (2010); Miguélez Cavero (2014) 182 - 185. - Zur Wirkung der dionysischen Mysterien in den Dionysiaka vgl. Gigli Piccardi (1998). 


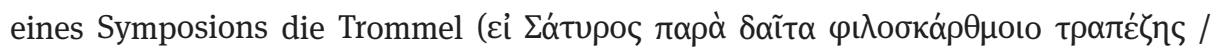

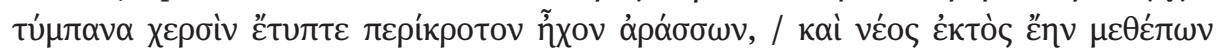

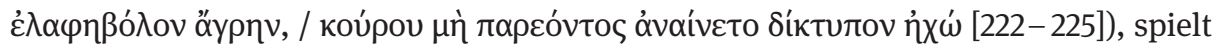

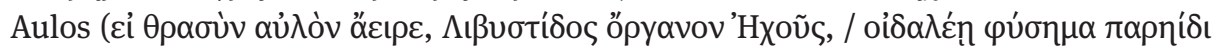
$\lambda \varepsilon \pi \tau o ̀ v ~ i a ́ x \lambda \omega \nu$ [231f.] $)^{93}$ und tanzt (238-241). Ampelos vollführt außerdem anlässlich

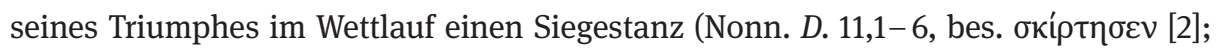

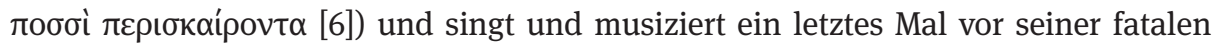

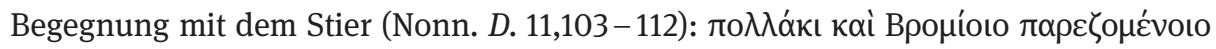

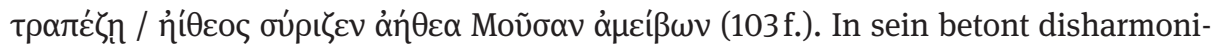

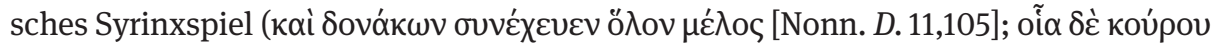

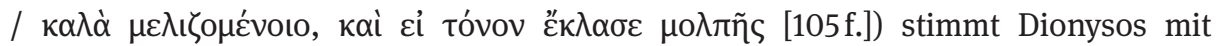
rhythmischem Klatschen ein (107-112). Der Satyr erweist sich in diesen Funktionen als Teil der dionysischen Welt, die er durch die typischen Instrumente und deren ungewöhnliche Missklänge reflektiert. Die Partizipation am dionysischen Kosmos wird rhetorisch wirksam inszeniert, wenn Ate in ihrer Rede Ampelos' Hybris anstachelt und seine Integration in den Kult in Frage stellt (Nonn. D. 11,119-129):

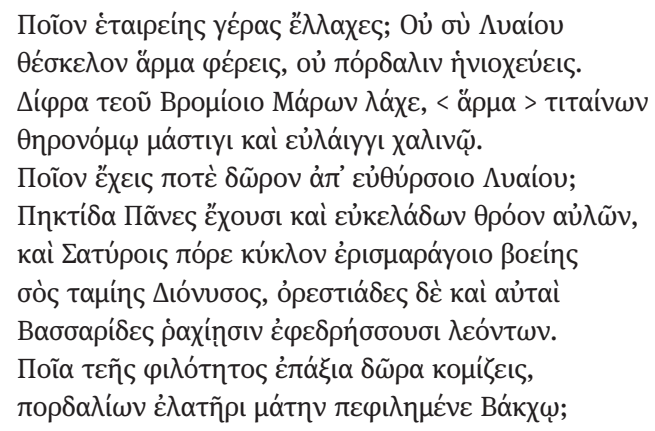

\begin{abstract}
Welches Freundschaftsgeschenk hast du erhalten? Du lenkst nicht den (120) wunderbaren Wagen des Lyaios, du führst nicht den Panther im Gespann. Den Platz bei deinem Bromios nahm Maron ein, der den Wagen mit tierbändigender Peitsche und festen Zügeln lenkt. Welches Geschenk hast du von Lyaios mit dem schönen Thyrsos erhalten? Die Pane haben eine Rohrflöte und den Klang der wohlklingenden Auloi, (125) und den Satyrn gab er das Rund der laut dröhnenden Pauke, dein Bezwinger Dionysos, und selbst die Bassariden von den Bergen sitzen auf Löwenrücken. Welche deiner Freundschaft würdigen Geschenke erhältst du? Du wirst von Bakchos, dem Lenker des Panthergespanns, ganz umsonst geliebt?
\end{abstract}

So wie die dionysische Welt hier ihre Definition durch die Musikinstrumente, die wilden Tiere und den Thyrsos erhält, erfolgt die Verbindung zum dionysischen Kult über Instrumente auch in der ersten Trauerrede des Dionysos, in welcher betont wird, dass der nunmehr verstorbene Ampelos nicht mehr den gewohnten Tätigkeiten

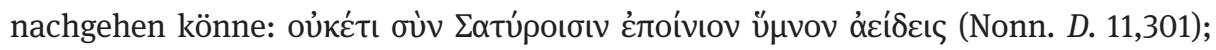

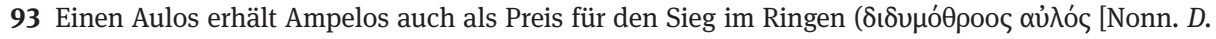

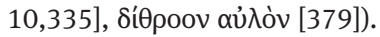




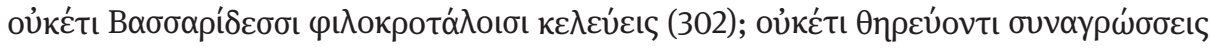

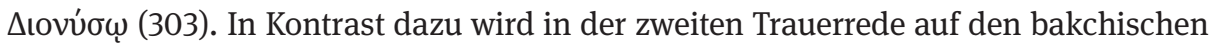

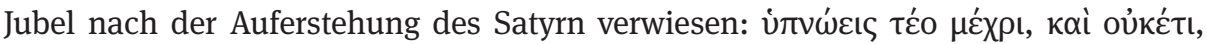

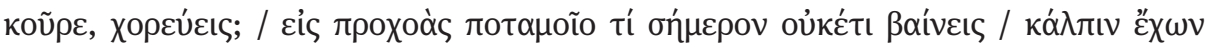

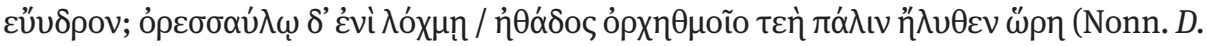
11,331-334). Auf die Kultäußerung in Form von Musik, Rhythmus und Tanz nimmt auch die Prophezeiung der Atropos Bezug, in der das Aulosspiel als hymnischer Preis

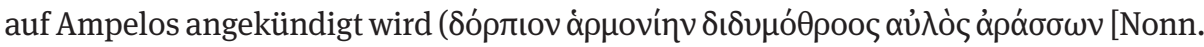

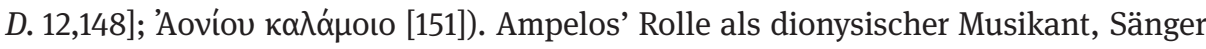
und Tänzer nimmt den zukünftigen dionysischen Kult und seine Ausprägungen vorweg, nicht nur sein Aussehen, sondern auch sein typisches Verhalten weist ihn als Angehörigen dieses Kultes aus.

Nonnos entwirft das dionysische Milieu nicht nur auf der Grundlage von Musik, sondern zieht auch dionysische Tiere und Attribute hinzu: Löwe (Nonn. D. 10,329; 11,68, 79, 126, 300, 337 f.), Tiger (11,69f.), Bär (66f., 78), Panther (64, 78, 120, 129, 341f.), Hirsch (344f.) und Wildschwein (346) erscheinen entweder im Jagd-Kontext (10,224) oder im Tross des Dionysos; der Stier spielt sogar einen wesentlichen Part in der Handlung, indem er für Ampelos' Todesritt verantwortlich ist (11,80, 147-223, 256, 288, 294, 349 f.). Von den Attributen des Dionysos verwendet Ampelos Narthex und Thyrsos

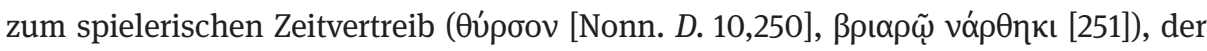
Thyrsos dient ferner als Wendemarke beim Wettlauf ( $\theta$ úpoov [397]). ${ }^{94}$ Die dionysische Ausstattung von Ampelos, Leneus und Kissos wird durch Zimbeln, Hirschfelle, Syrinx und Pauke sowie durch den rötlichen Flusssand des Paktolos komplettiert, die allesamt als Preise im Wettlauf ausgesetzt werden (Nonn. D. 10,386-392).

In der Einarbeitung all dieser dionysischen Kultelemente geht es Nonnos keineswegs um die Vermittlung paganer Kultpraktiken mit antichristlicher Tendenz, sondern vielmehr um die Demonstration seines literarischen Könnens, ${ }^{95}$ da die dionysischen Erkennungszeichen vor allem im Hinblick auf die Komposition der Ampelos-Figur eingesetzt werden. Einen Höhepunkt in diesem narrativen Netz bildet die kultische Einkleidung des Ampelos mit dionysischen Insignien, die der Satyr zunächst eigenmächtig und unautorisiert vollzieht (Nonn. D. 11,56-70):

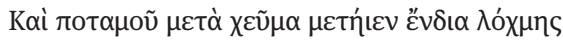

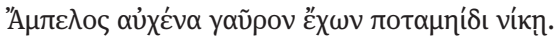

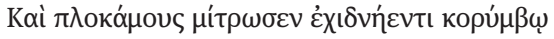

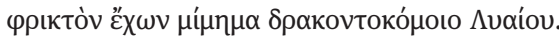

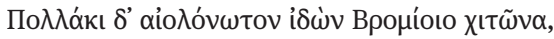

60

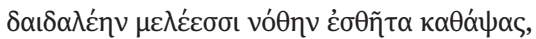

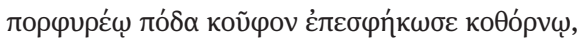

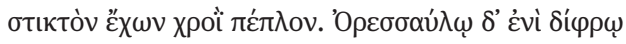

94 In Nonn. D. 11,354 präsentiert sich Eros in dionysischem Kleid auf einen Narthex-Stengel gestützt

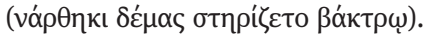

95 Vgl. Vian (1988a) 408 (453); Caprara (1999) 199 f. 


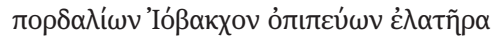

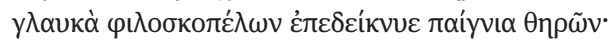

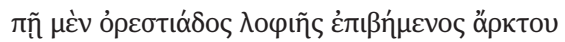

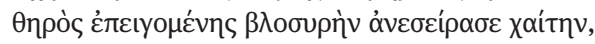

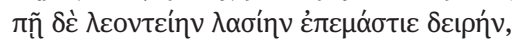

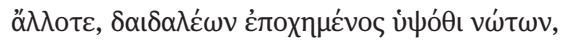

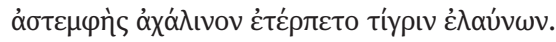

65

70

Und Ampelos stieg zu Mittag aus dem Fluss, begab sich ins Dickicht und hatte einen stolzen Hals vom Sieg im Fluss. Und er bekrönte seine Locken mit einer schlangenartigen Kopfbedeckung und hatte das schaurige Aussehen des drachenhaarigen Lyaios. (60) Und oft sah er das Gewand des Bromios mit gescheckter Rückenseite und zog sich ein bunt gewirktes, unschickliches Gewand über seine Glieder, band sich einen purpurnen Stiefel an den leichten Fuß und hatte einen von Farbe bunt gesprenkelten Peplos. Und auf dem Wagen von bergbewohnenden Panthern hielt er Ausschau nach Iobakchos, dem Wagenlenker, (65) und führte ihm glänzende Spiele mit Felsen liebenden Tieren vor. Er ging auf eine felsige Anhöhe, und als ein wilder Bär heranstürmte, schüttelte er seine haarige Mähne und peitschte das zottige Löwenfell; ein andermal ritt er ganz oben auf dem gesprenkelten Rücken, (70) und unerschütterlich, voll Freude und ohne Zügel trieb er einen Tiger voran.

Das dionysische Gebaren, das hier ohne Zustimmung des Gottes geschieht und Ausdruck von Ampelos' Hybris ist, ${ }^{96}$ ist Vorverweis auf die späteren Eigenschaften der Rebe und das Kommen des Getränks und wird vom Dichter bewusst als narrative Klammer innerhalb der Episode eingesetzt. Die in Ampelos' Porträt vorweggenommenen Eigenschaften des Weines (Nonn. D. 10,175-192) ${ }^{97}$ setzen sich im Ringkampf fort, in welchem die Kletterfähigkeit der Pflanze (348-350) sowie der Weinlaubkranz

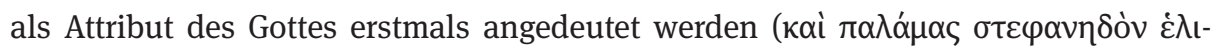

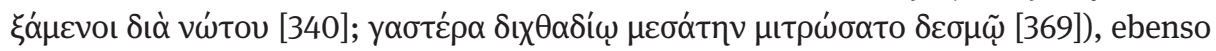
wie im Wettschwimmen, für das Dionysos selbst dem Sieger einen Siegeskranz in

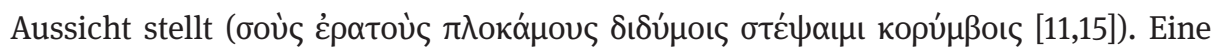
Steigerung erfahren die Vorwegnahmen in der Szene, in der Ampelos den Stier schmückt (Nonn. D. 11,167-184):

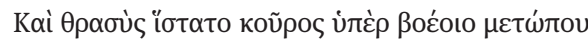

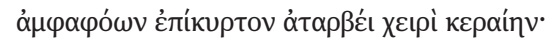

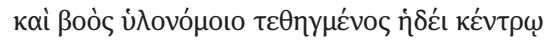

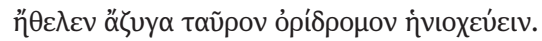

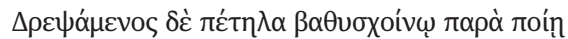

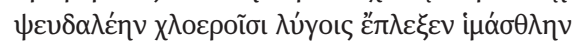

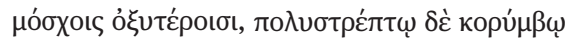

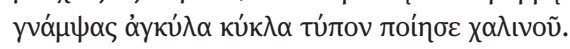

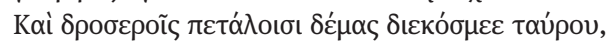

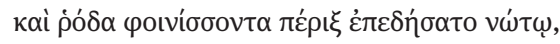

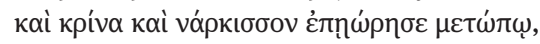




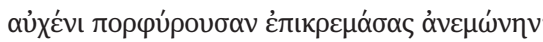

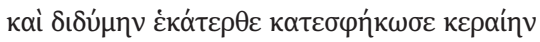

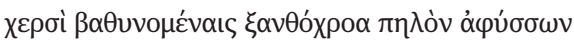
180

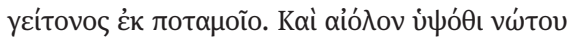

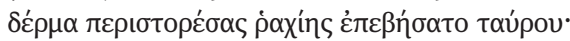

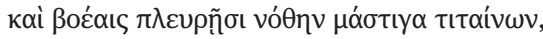

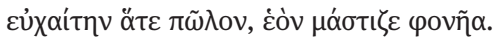

Und verwegen trat der Knabe hin zum Kopf des Rindes und berührte mit furchtloser Hand das gebogene Horn. Geschärft durch den süßen Stachel des Waldrindes (170) wollte er den Stier ohne Joch von den Bergwegen lenken. Er brach Blätter ab und flocht aus Binsengras vom hohen Schilf einer Wiese eine lange Peitsche, jedoch keine richtige, sondern aus grünen Zweigen des Mönchspfeffers, um Rinder anzutreiben, und an der vielverzweigten Spitze formte er einen Bogen und schuf eine Art Zügel. (175) Und mit feuchten Blättern schmückte er den Leib des Stieres, purpurne Rosen band er um seinen Rücken, Lilien und Narzissen ließ er über die Stirn baumeln, an den Hals hängte er eine purpurne Anemone. Die zwei Hörner umhüllte er auf beiden Seiten, (180) indem er mit den tief eingetauchten Händen gelbfarbigen Schlamm aus dem benachbarten Fluss schöpfte. Und ganz oben auf dem Rücken breitete er eine Felldecke aus und stieg auf den Nacken des Stieres. Und er streckte über die Flanken des Rindes die falsche Peitsche aus; und als ob es ein Fohlen mit schöner Mähne wäre, peitschte er seinen Mörder.

Beim Aufeinandertreffen von Ampelos und dem Stier findet sich neben den Vegetationsmotiven auch ein Vorverweis auf die Pflege des Weinstocks durch Bewässerung, wenn der Stier den Satyrn mit Wasser besprengt und so die Technik des Wasserschöpfens mittels eines von einem Rind angetriebenen Schöpfrades andeutet (Nonn. D. 11,161-166). ${ }^{98}$ Direkte Bezüge auf den Wein unmittelbar vor der Metamorphose stellt

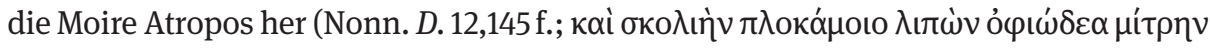

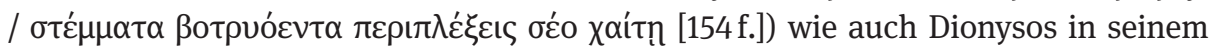
abschließenden Enkomion (248-250). Nach weiteren Hinweisen auf den Wein - die blutige Opferung des Hirschkalbs durch die Schlange (Nonn. D. 11,91-93), das Blut des verstorbenen Ampelos (222f.), die Ankündigung des Stieropfers als dionysischer Kultpraxis (264-270) ${ }^{99}$ sowie das Gärtnergleichnis des Eros (366-368) - erfolgt die tatsächliche Aufnahme des Ampelos in den dionysischen Kult bei dessen Ausstattung mit den bekannten Attributen unmittelbar nach seinem Tod (230-252): ${ }^{100}$ Die Einkleidung mit Hirschfell, Blumen, Thyrsos und Ambrosia, die Dionysos an Ampelos vornimmt, bringt die Erzählung um den Gott und seinen Lieblingssatyrn auf einen finalen Höhepunkt; Ampelos wird in seiner neuen Erscheinungsform als Weinstock

98 Vgl. Gigli Piccardi (2003) 734, 766f. Anm. ad 161-166.

99 Auf die Opferung des Stieres wird auch an anderen Stellen in den Dionysiaka angespielt: Kadmos opfert eine Kuh (Nonn. D. 4,348-355 und 5,1-34); Aristaios opfert Weihrauch, Stierblut und Honig für Zeus Ikmaios (5,270-273); bei der Hochzeit von Autonoe und Aristaios wird ein Rind geopfert (281f.); Semele opfert nach einem Traum ein Rind und einen Ziegenbock (7,161-170); im Traum der Agaue wird ein Rind geopfert (44,84-106); vgl. auch Nonn. P. 4,97 - 103, wo Jesus der Samariterin die Aufkündigung des blutigen Opfers verkündet, siehe dazu Caprara (1999) $198 \mathrm{f}$.

100 Für Text und Übersetzung siehe S. $123 \mathrm{f}$. 
zum offiziellen Mitglied des dionysischen Kultes. ${ }^{101}$ Die narrative Linie des Dionysischen beginnt bereits in der Eingangsszene um die schwimmenden Satyrn, deren Sprungspiele im Paktolos den späteren Kelterprozess vorwegnehmen (Nonn. D. 10,139-174); das Flusswasser der beiden Schwimmszenen, das symbolisch das dionysische Getränk andeutet, durchläuft gleichsam eine Wandlung von Wasser zu Wein.

Mit dem Tod und der Metamorphose des Ampelos gelangt die dionysische Erzähllinie nicht zu ihrem Abschluss: An Ampelos' Initiation schließt die eigentliche Kultbegründung an, im Zuge derer die einschlägigen Gegenstände - das Rinderhorn als Trinkgefäß und der aus Weinlaub geflochtene Kranz - ihre ihnen zugedachte Funktion erhalten (Nonn. D. 12,193-206). ${ }^{102}$ Den Höhepunkt der ersten Weinlese bildet der Alternativmythos, in welchem die Satyrn unter Dionysos' Anleitung die Trauben keltern und vom Saft kosten (Nonn. D. 12,345-362):

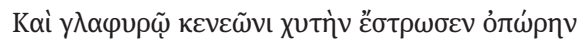

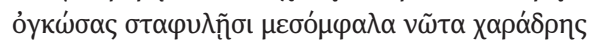

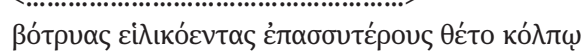

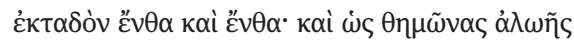

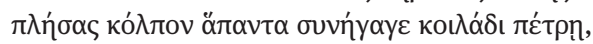

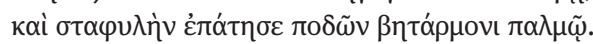

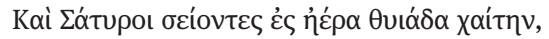

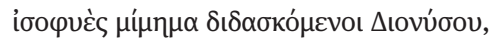

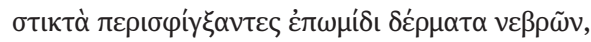

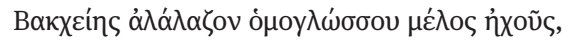

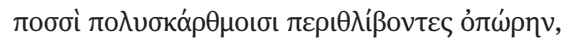

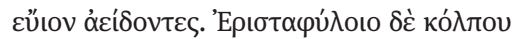

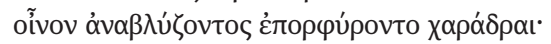

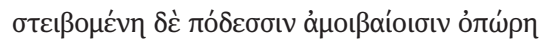

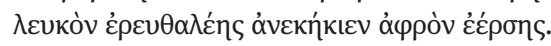

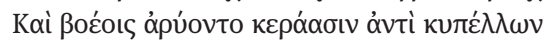

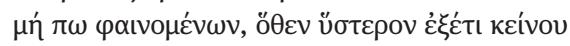

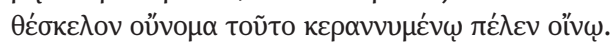

(345) Und in den gewölbten Hohlraum breitete er die ausgeschütteten Früchte und ließ den Pegel der Traube bis zur Mitte ansteigen. <...> Dann legte er die Trauben rundum der Reihe nach eine nach der anderen in die Höhlung, hierhin und dorthin ausgebreitet, und wie mit einem Haufen an Getreide füllte er seinen Gewandbausch und leerte alles in den ausgehöhlten Felsstein. (350) Und mit dem tanzenden Schritt seiner Füße trat er die Trauben, und die Satyrn schüttelten ihre wilde Mähne durch die Luft, genau nach dem Vorbild des Dionysos unterwiesen. Sie banden sich gesprenkelte Hirschfelle um die Schulter, jauchzten im selben Ton die Melodie eines bakchischen

101 Auch mit der Einkleidungsszene des Ampelos knüpft Nonnos an bestehende Traditionen an. Eine literarische Parallele liegt in Apul. met. 8,7 vor, wo eine Witwe über ein Bildnis ihres verstorbenen Mannes in dionysischen Kleidern verfügt: diesque totos totasque noctes insumebat luctuoso desiderio et imagines defuncti, quas ad habitum dei Liberi for $<$ m $>$ averat; belegt sind zudem Grabepigramme, Statuen und Reliefs, die den Verstorbenen jeweils als Dionysos verkleidet zeigen; zu den Zeugnissen siehe Guettel Cole (1993) 286f.

102 Für Text und Übersetzung der Stelle siehe S. $54 \mathrm{f}$. 
Liedes (355) und traten in flinken Sprüngen mit den Füßen die Früchte, ein Jubellied singend. Und von den feinen Trauben in der Grube, die den Wein aufschäumen ließen, kamen rotfarbige Bäche. Vom Wechselschritt der Füße wurde die Ernte zertreten, und weißer Schaum schoss aus dem roten Saft hervor. (360) Und sie schöpften mit ihren Rinderhörnern statt mit Bechern, die es noch nicht gab, von denen noch später der gemischte Wein seinen erstaunlichen Namen erhielt.

Ampelos’ Gesang, Musik und Tanz - Präfigurationen dionysischer Ausdrucksformen und Kultäußerungen - werden durch die ekphrastische Schilderung des Pressvorgangs ergänzt und durch den die Ampelos-Episode beschließenden narrativen Komplex der Auswirkungen des rituellen Weinkonsums abgerundet (Nonn. D. 12,363-379):

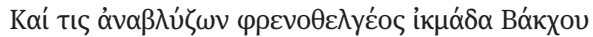

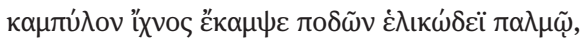

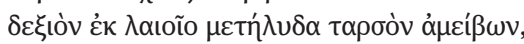
365

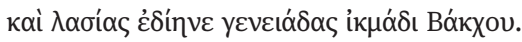

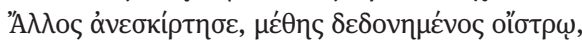

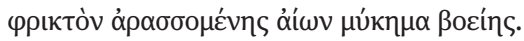

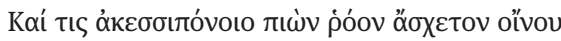

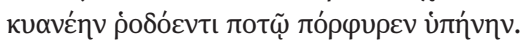

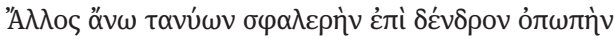

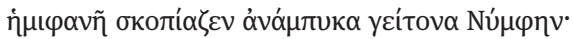

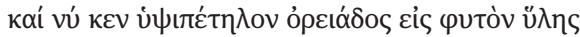

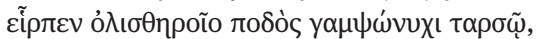

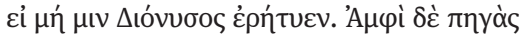

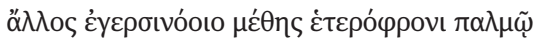

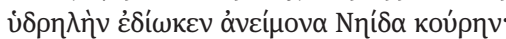

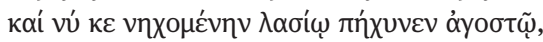

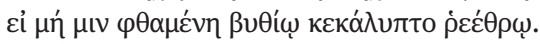

Und einer, im Sinn betört, rülpste den Saft des Bakchos herauf und zog eine gewundene Spur mit der gekrümmten Fußsohle, (365) indem er das Bein abwechselnd von links nach rechts wandte und die struppigen Wangen mit dem Saft des Bakchos benetzte. Ein anderer sprang auf, getroffen vom Stachel des Rausches, weil er das schaurige Dröhnen des Trommelschlags hörte. Wieder einer trank unkontrolliert einen ganzen Strom von besänftigendem Wein (370) und färbte seinen schwarzen Schnurrbart mit dem roten Trank purpurn. Ein anderer ließ seinen unsteten Blick auf einen Baum hinaufschweifen und hielt Ausschau nach einer halb sichtbaren Nymphe in der Nähe, ohne Stirnband; und jetzt wäre er mit den gebogenen Krallen an seinen Füßen auf den hochragenden Waldbaum geklettert ohne Halt für den Schritt, (375) wenn Dionysos ihn nicht daran gehindert hätte. Und um die Quellen herum verfolgte ein anderer mit rasender Hand, voll von aufstachelnder Trunkenheit, eine klatschnasse, unbekleidete Naiade; und jetzt hätte er die Schwimmende mit seinem haarigen Arm umfasst, wenn sie ihm nicht zuvorgekommen wäre und sich in der tiefen Strömung verborgen hätte.

Die Illustration des Zustands der Trunkenheit, die in der Verfolgung der Nymphen und Najaden gipfelt (Nonn. D. 12,382-393), erfolgt in der Darstellung des Satyr-Kollektivs

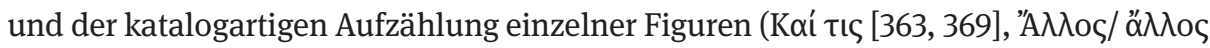
[367, 371, 376]), einer Technik, mit der Nonnos auf die Eingangsszene der AmpelosEpisode mit den badenden Satyrn rekurriert (10,148-174). Diese direkte Linie vom Beginn der Ampelos-Episode zum Ende des 12. Buches bindet den Alternativmythos an 
die Ampelos-Episode im engeren Sinn, indem dieser in der Tradition der Lehrdichtung nun eine technische Auseinandersetzung mit dem Thema Genese des Weines liefert. ${ }^{103}$ Die Doppelerzählung, die die Entstehung des Weines zum eigentlichen Erzählkern der Bücher 10-12 macht, lenkt die Aufmerksamkeit weg von Ampelos hin zum eigentlichen Protagonisten, der Gabe des Gottes, dem Wein.

\subsection{Verbindungen zu weiteren Büchern der Dionysiaka}

Gleichsam als alter ego des Ampelos sind einige weitere Figuren in den Dionysiaka konzipiert, die eine oder mehrere Eigenschaften mit diesem teilen: in der AmpelosEpisode selbst Leneus und Kissos, die im Wettlauf gegen Ampelos antreten. Analog zu Ampelos nimmt Nonnos zur Komposition dieser Figuren nicht nachweislich bei konkreten literarischen Vorbildern Anleihen, was insbesondere auf Leneus, die Personifikation des Keltervorgangs, zutrifft, der als Figur ausschließlich bei Nonnos belegt und ansonsten lediglich durch die Epiklesen „Leneus“ und „Lenaios“ für Dionysos bezeugt ist. ${ }^{104}$ Auch Leneus hat eine ad hoc konstruierte Genealogie (Nonn. D. 14,99) und tritt nur in der Wettlaufszene als eigenständig handelnde Figur in Erscheinung (bes. 10,400-430), wo er durch das Eingreifen von Dionysos zugunsten seines Lieblings Ampelos den zweiten Platz erringt (422f., 427). ${ }^{105}$ Im Gegensatz zu ihm wird Kissos, der Efeu, in mehreren Zeugnissen der bildenden Kunst und Literatur fassbar. ${ }^{106}$ In den Dionysiaka ist er Teilnehmer am genannten Wettrennen, wird unmittelbar nach Ampelos' Metamorphose in Efeu verwandelt (Nonn. D. 12,97-102, 188 192) und erfährt insofern ein zu Ampelos paralleles Schicksal, als er in Gestalt einer Pflanze wiedergeboren wird und bereits in seiner satyrhaften Erscheinungsform über später für die Pflanze typische Fähigkeiten verfügt: Die Leichtfüßigkeit und Beweg-

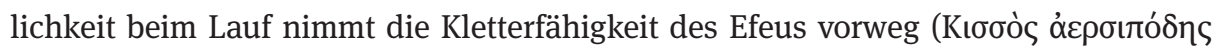

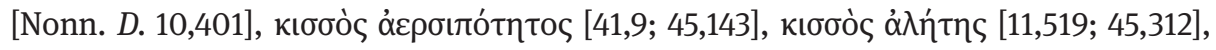

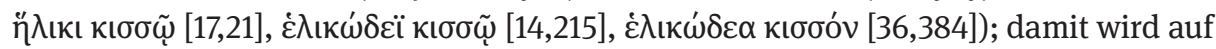
das narrative Ziel der Episode hingearbeitet: die Einverleibung des Efeus in den dionysischen Kult ${ }^{107}$ sowie die Ausstattung des Dionysos und des Kissos mit den

103 In der hellenistischen Dichtung haben nebeneinanderstehende Mehrfachmythen stets narrative Funktion, vgl. z. B. zu Ovid Loehr (1996) 368 f.

104 Siehe Nonn. D. 14,99, 392; 29,229, 260; vgl. Vian (1995) 77 Anm. 3, 78 Anm. 1; Gigli Piccardi (2003) 726 Anm. ad 399-404. Zu den Personifikationen dionysischer Begleiter siehe auch Miguélez Cavero (2014).

105 Zur Wettlaufszene siehe S. 110-114.

106 Zu den Quellen für Kissos vgl. Vian (1995) 78; Gigli Piccardi (2003) 726f. Anm. ad 399-403.

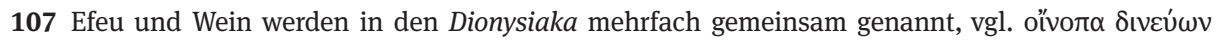

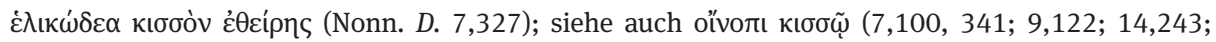

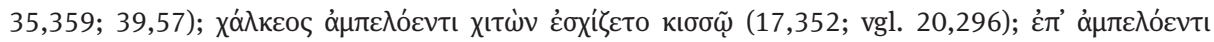

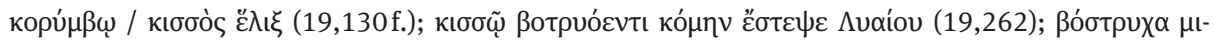




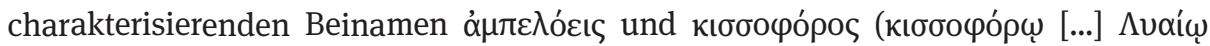
$[12,109]){ }^{108}$

Das Faktum, dass Kissos häufiger belegt ist als Ampelos, gab Anlass zur Annahme, dass die Personifikation des Efeus keine Erfindung des Nonnos sei. ${ }^{109}$ Tatsächlich lässt

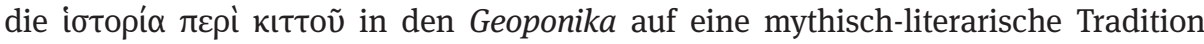
schließen, indem diese einen Kissos-Mythos schildert, der in den inhaltlichen Details Ähnlichkeiten mit der Ampelos-Erzählung aufweist: Kissos, der Begleiter des Dionysos, stürzt beim Tanz und wird von der Erdgöttin in Efeu verwandelt $(G p .11,29):{ }^{110}$

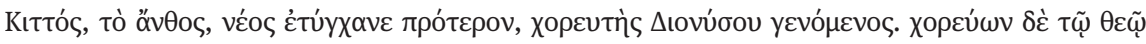

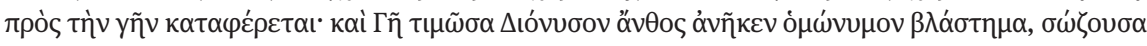

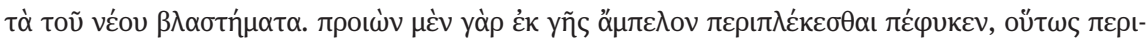

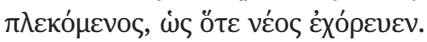

Efeu, die Pflanze, war früher ein junger Mann, ein Tänzer bei Dionysos. Aber als er für den Gott tanzte, stürzte er zu Boden, und Gaia ließ, um Dionysos zu ehren, mit demselben Namen eine Pflanzenblüte wachsen und bewahrte so die Blüte des Jünglings. Denn aus der Erde hervorgekommen, konnte er sich um den Weinstock winden, und so sich windend, als würde ein Jüngling tanzen.
\end{abstract}

Wie auch für Ampelos kann die Existenz eines einzigen konkreten literarischen Vorbildes nicht mit Sicherheit ausgeschlossen werden, dennoch scheint Nonnos' Vorliebe für Adaptationen aus unterschiedlichen Quellen und Traditionen besonders für den souveränen Umgang mit mehreren mythischen und literarischen Mustern zu sprechen. Die Motive, die Ampelos, Leneus und Kissos gemeinsam sind, treten auch in anderen narrativen Kontexten in den Dionysiaka in Erscheinung und werden, gleichsam zu literarischen Gemeinplätzen verselbstständigt, in Verbindung mit anderen Figuren angewandt und verbinden oftmals räumlich und thematisch weit auseinanderliegende Passagen.

Das Motiv des Götterlieblings wird in der Gestalt des Hymenaios neuerlich thematisiert, der in Nonn. D. 13,83-121 als Heerführer der Boioter und, Ampelos ver-

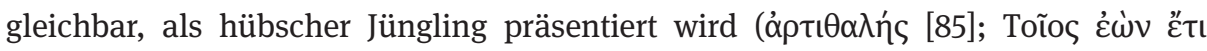

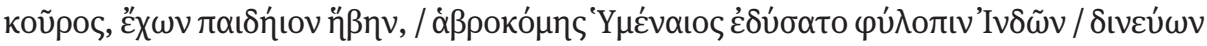

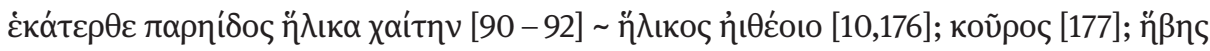

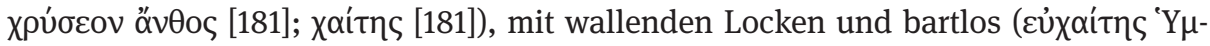

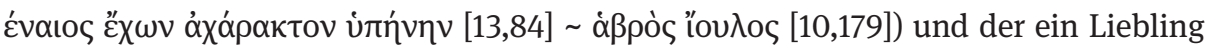

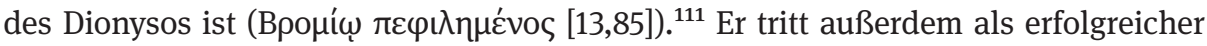
(Wett-)Kämpfer in Erscheinung (15,160-166; 24,88-91; vgl. auch den Sieg im Bo-

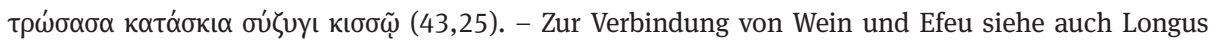
4,2,3; Q. S. 14,175 - 178; vgl. auch Kerényi (1994) 54f.; Vian (1995) 71 Anm. 3; Otto (2011) 139 - 143. $108 \mathrm{Zu}$ кıббофópoৎ für Dionysos vgl. Pi. O. 2,27; Opp. C. 1,365; vgl. auch Nonn. D. 43,67; Ar. Th. 988;

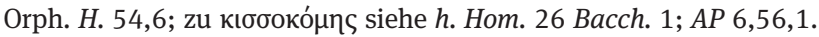

109 Vgl. Stegemann (1930) 156 Anm. 106.

110 Text: Lelli (2010) 672 Übersetzung: die Vf.

111 Zu Hymenaios siehe Vian (1995) 217f. Anm. ad 83-92. 
genschießen anlässlich der Leichenspiele für Opheltes [37,722-749]) und wird stets in

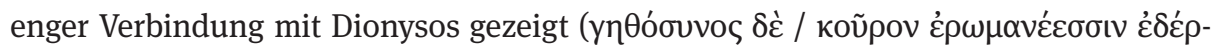

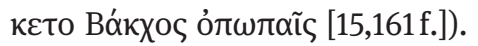

Die ausführlichste Szene zu Hymenaios und Dionysos findet sich im Rahmen der Indienkämpfe in Nonn. D. 29,15-178, wo Nonnos sich neuerlich mit seinem Vorbild Homer auseinandersetzt und die Szene mit dem Pfeilschuss des Pandaros auf Menelaos aus Hom. Il. 4,104-147 für seine eigene Erzählung umformt: Nach der Aristie des Hymenaios (Nonn. D. 29,15-21) kämpfen dieser und Dionysos Seite an Seite (2248), bis schließlich der Bogenschütze Melaneus den Jungen unglücklicht trifft (49-86) und der Pfeil nur durch das Eingreifen dreier Götter, des Zeus, des Dionysos und der Aphrodite, gebremst wird, sodass weder Dionysos noch der Jüngling ernsthaft verletzt werden. An die Szene der Trauer des Dionysos um seinen Liebling (Nonn. D. 29,87-150) schließen die Heilung des Hymenaios durch Efeu und Wein (151-162) sowie sein erneuter Eintritt in den Kampf an der Seite des Dionysos an (162-178). Mit der Pfeilschussszene im 29. Buch liefert Nonnos lediglich eine Skizze der Erzähllinie der iliadischen Pandaros-Szene, in den Einzelheiten distanziert er sich von seinem Vorbild, ja verzerrt und persifliert dieses, wenn er im Unterschied zu Homer statt einer insgesamt drei Gottheiten zugunsten des Hymenaios eingreifen lässt. Nonnos spielt geradezu mit der Formensprache des epischen Genus: Dem abwesenden Inder-Führer hält er den omnipräsenten Dionysos entgegen, der sich sowohl als agierende Figur am Geschehen beteiligt als auch als allmächtiger Gott das Geschehen lenken kann; Dionysos verfügt über die volle Handlungsfähigkeit, indem er einerseits als Heerführer - dessen Trauerrede die Rede Agamemnons aus Hom. Il. 4,148 - 181 reflektiert ${ }^{112}$-, andererseits als Herr über Leben und Tod stilisiert wird, wenn er, die Rolle des Machaon in der Ilias übernehmend (Hom. Il. 4,193-219), den verletzten Hymenaios medizinisch versorgt.

Der homerische Hypotext wird auch insofern aufgebrochen, als Dionysos im kriegerischen Kontext der Pfeilschussszene nicht selbst als Kämpfer in Erscheinung tritt, sondern ähnlich wie in den Wettspielen gegen Ampelos in Nonn. D. 10 und 11 die erotischen Komponenten des Verhältnisses zwischen Dionysos und Hymenaios hervorgekehrt werden. ${ }^{113}$ In diesem Sinne ist das Hymenaios-Intermezzo als Reprise der Ampelos-Episode zu verstehen, die durch den gemeinsamen Kampf gegen die Inder die Wettspiele mit Ampelos reflektiert (Nonn. D. 29,15-48, 162-178 Nonn. D. 10,322$11,55)$ und das Trauer-Motiv um den geliebten Jüngling wieder aufnimmt (Nonn. $D$. 29,108-134 Nonn. D. 11,255 - 350), wobei Dionysos Hymenaios jedoch durch sofortige ärztliche Hilfe zu heilen imstande ist (Nonn. D. 29,151-163 Nonn. D. 11,351-12,397). Insbesondere in zwei Passagen greift Nonnos einzelne Motive aus der Ampelos-Episode auf, zieht sogar einen direkten Vergleich zwischen beiden Dionysos-Lieblingen und nennt auch im Porträt des Hymenaios einzelne Charakteristika, die bereits von

112 Vgl. Vian (1990) $205 \mathrm{f}$.

113 Vgl. Vian (1990) 198-208. Bereits bei seiner Präsentation wird das erotische Erscheinungsbild des Hymenaios hervorgehoben, vgl. Chuvin (1991) 41. 


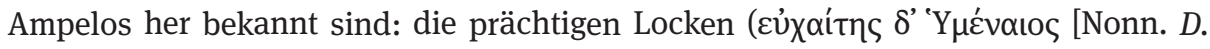

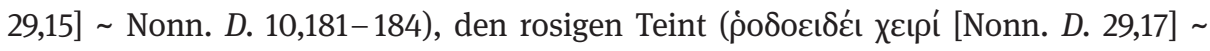

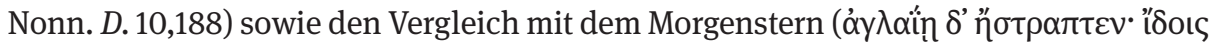

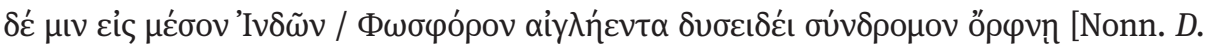
29,18f.] Nonn. D. 11,25). Die allumfassende Schönheit und die göttliche Kraft im

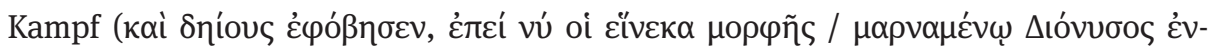

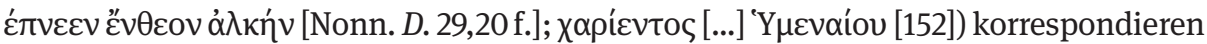
genauso mit dem Vorbild wie die Thematik der Sterblichkeit und Vergänglichkeit

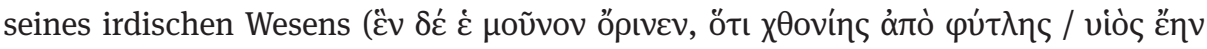

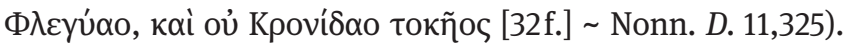

Unmissverständlich wird die Entsprechung der beiden Figuren auch durch zwei mythische Vergleiche mit Götterlieblingen, die einem Unfalltod zum Opfer fallen: Hyakinthos (Nonn. D. 29,95-99) und Adonis (135-138): ${ }^{114}$

'I

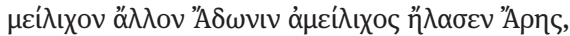

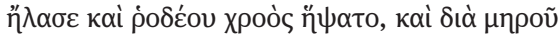

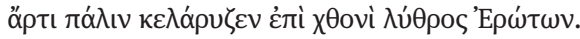

Sei gnädig, Kythereia! Nach dem verwegenen Sohn der Myrrhe (135) schlug der harte Ares einen anderen zarten Adonis, er schlug ihn und traf ihm die rosige Haut, und aus seinem Schenkel sprudelte sogleich das Blut der Eroten auf die Erde.

In Nonn. D. 29,142f. erfolgt ein abermaliger Vergleich mit Hyakinthos: Фог̃ßov ع̋ $\alpha \alpha \tau$ '

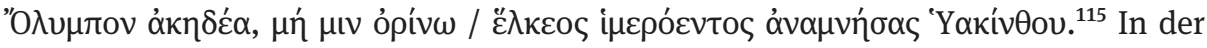
Diskrepanz zwischen dem tödlichen Schicksal der genannten Vergleichsfiguren und der letztlich harmlosen Verwundung des Hymenaios lässt Nonnos sein Interesse an karikierenden Überzeichnungen und Neuinterpretationen bekannter Mythen und überkommener narrativer Strategien durchscheinen.

Eine Parallele zwischen der Hymenaios- und der Ampelos-Episode liegt auch in Dionysos’ Trauerrede auf den Verletzten vor, die ähnlich wie die beiden Trauerreden auf Ampelos rhetorisch durchkomponiert ist: Der Aufzählung der Begleiter, die Dionysos eher opfern würde als Hymenaios (Nonn. D. 29,109-117), folgt die Mutmaßung über die Ursache des erneuten Unglücks (Neid der Hera [120 -126]) und die Ankündigung der Rache am Schützen (127-134). Die Rede zieht auch einen direkten Vergleich

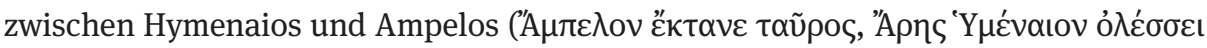
[Nonn. D. 29,108]) und liefert zudem eine vage Erinnerung an das Schicksal des Satyrn

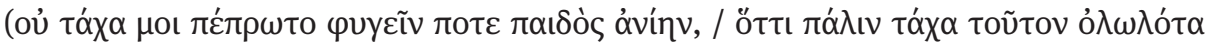
$\pi \alpha \tilde{\delta} \delta \alpha$ yoń $\sigma \omega$ [118f.]). Die thematische Schwerpunktsetzung in beiden Episoden, der Kampfszene mit Hymenaios und den Sportwettkämpfen mit Ampelos, liegt nicht in der bloßen Imitation typisch epischer Szenen. Nonnos geht jeweils über die engen

114 Für Text und Übersetzung von Nonn. D. 29,95-99 siehe S. 79.

115 Zum Einfluss des Hyakinthos-Mythos auf die Hymenaios-Episode vgl. D’Ippolito (1964) 145. 
Grenzen des homerischen Epos hinaus und fügt eine stark von hellenistischen Dichtungsformen geprägte Note hinzu. ${ }^{116}$ Die Hervorhebung des Themenbereichs Liebe und Erotik gipfelt in Dionysos' Feststellung, dass Liebeskummer tiefere Wunden als der Kampf mit Waffen hervorrufen könne (Nonn. D. 29,146-150). Das Zwischenspiel um Hymenaios und Dionysos wird zum gelehrten Spiel mit den Konventionen unterschiedlicher literarischer Genera.

Die Dionysiaka bieten neben Ampelos, Leneus und Kissos noch weitere Figuren, denen eine Metamorphose in den Wein oder verwandte Stoffe widerfährt: König Staphylos („Weintraube“) und seine Familienangehörigen, seine Gattin Methe („Rausch“), sein Sohn Botrys (,Weinbeere“) und der Diener Pithos („Fass“), werden in die ihren Namen entsprechenden Begleiter des Weines verwandelt (Nonn. D. 18-19). ${ }^{117}$ Durch den Vergleich mit Hyakinthos zieht Nonnos eine direkte kompositorische Verbindung von Ampelos über Staphylos zu Hymenaios. Das Schicksal aller drei Figuren wird durch den Mythos vom unglücklichen Tod des Apollon-Lieblings reflektiert. ${ }^{118}$ Mit der Staphylos-Episode beschließt und vollendet Nonnos die Erzähllinie der Erfindung des Weines, ${ }^{119}$ die sich von der ersten Ankündigung durch Zeus in Nonn. D. 7,71-105 über die Genese des Weinstocks in der Ampelos-Episode bis zu den Büchern 18 und 19 spannt. Ein Nachhall auf Personifikationen des Weines und verwandter Sujets findet sich ferner in Nonn. D. 43,52-68, wo ein Katalog ausschließlich sprechende Namen bietet, die in Zusammenhang mit der Rebe, dem Wein und seinem Aussehen stehen: Oineus (der Sohn des Ereuthalion und der Phyllis), Helikaon, Oinopion und sein Bruder Staphylos (zwei Söhne des Oinomaos) sowie Melanthios (der Sohn der Oinone), werden als Heerführer des Dionysos genannt. ${ }^{120}$

Als Variation zur Staphylos-Geschichte bietet der Dichter die Begegnung mit Ikarios, seiner Tochter Erigone und deren Hund auf (Nonn. D. 47,34-264). ${ }^{121}$ Der gewaltsame Tod des attischen Bauern und ersten Weintrinkers spiegelt Ampelos' Schicksal. Anstatt jedoch wie in der Ampelos- und Staphylos-Episode als Schlusspunkt eine Metamorphose zu setzen, werden die Figuren durch Katasterismoi aus ihrer misslichen Lage befreit: Staphylos wird zum Sternbild des Bootes, Erigone zur Jungfrau mit der Ähre und ihr Hund zum Stern Sirius (Nonn. D. 47,246-264). Mit der Verbindung der Sternbilder und des dionysischen Kosmos wird auf den Reifeprozesses des Weines im Hochsommer

116 Vgl. Vian (1990) 202; Hernández de la Fuente (2008) 85 f.; Lovatt (2013) 282 f.

117 Zum Besuch des Dionysos bei Staphylos vgl. Ouwaroff (1817) 48-52; Keydell (1932) $184 \mathrm{f}$. (496f.); Fauth (1981) 136-139; Chuvin (1991) 109-193; Shorrock (2001) 161-164; Hopkinson u. Vian (1994) 3 - 8; Faber (2004). - Mit den Gastszenen um Dionysos und Brongos, Staphylos und Ikarios greift Nonnos auf eine hellenistische Tradition zurück, vgl. Abel-Wilmanns (1977) 101-107; Hollis (1990) 341-343; Shorrock (2001) 146-156.

118 Zu Staphylos und Hyakinthos vgl. Lasek (2009) 85 Anm. 48; vgl. außerdem S. 74-79, 175 und 237. 119 Vgl. Vian (1995a) 213f. (564).

120 Vgl. Accorinti (2004) 294f. Anm. ad 52 - 68; Chuvin u. Fayant (2006) 190 - 192. - Zum Mythos der Erfindung des Weines durch Oinopion vgl. Kerényi (1994) 62.

121 Zur Ikarios-Episode vgl. Fauth (1981) 132-135; Shorrock (2001) 100f.; Spanoudakis (2007); Borgeaud (2011). 
verwiesen. Der Ikarios-Mythos wird ebenso überzeugend in den nonnianischen Dionysos-Mythos eingepasst wie das hellenistische Genus des Epyllions in den Erzählfluss der Dionysiaka, das der Dichter in derartigen Gastszenen zur Anwendung bringt. ${ }^{122}$

Die Motive Wein und Metamorphose begegnen auch im Zusammenhang mit Ambrosia, einer Nymphe im Gefolge des Dionysos und dessen Amme, die, verwandelt in einen Weinstock, Dionysos’ Widersacher Lykurg überwältigt (Nonn. D. 21,1-62, 153f., 295-298). ${ }^{123}$ Wie bei Ampelos wird auch hier der Verwandlungsvorgang beschrieben (Nonn. D. 21,28-32):

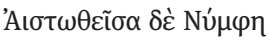

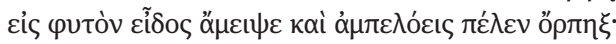

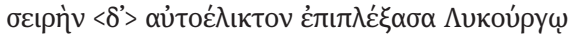

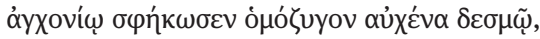

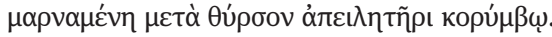

Und indem die Nymphe verschwand, verwandelte sie ihre Gestalt in eine Pflanze und wurde ein Schössling des Weinstocks. (30) Wie ein Strick flocht sie sich von selbst um Lykurg, schnürte mit würgender Fessel seinen Hals zusammen und kämpfte nach dem Thyrsos nun mit bedrohlicher Traube.

Elemente aus der Ampelos-Episode werden insofern wiederaufgenommen, als das

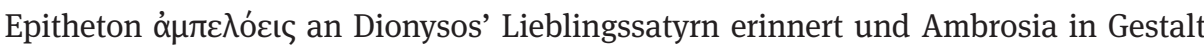
der Weinrebe eine Rede auf ebendiese anschließt, in der sie als besondere Eigenschaft des Weines dessen universelle Anwendbarkeit auch als Angriffs- und Verteidigungswaffe hervorhebt (Nonn. D. 21,36-52). Diese Rede darf als Fortsetzung und Ergänzung der die Ampelos-Episode beschließenden Dionysos-Rede gewertet werden und fügt sich mühelos in den enkomiastischen Zug der Dionysiaka ein. ${ }^{124}$

Bereits von Rudolf Keydell wurde für die Ampelos-Episode festgestellt: „[...] die ganze Erzählung betont stark den Wandel vom Tode zum Leben. “125 Tatsächlich lässt sich das Sujet der Wiederauferstehung durch die gesamten Dionysiaka verfolgen, von Zagreus über Ampelos bis hin zur Apotheose des Dionysos am Schluss des Epos. ${ }^{126}$

122 Vergleichbare Mythen um gastliche Aufnahme, Entstehung und Weitergabe des Weines finden sich in Zusammenhang mit Oineus, der ähnlich wie Ikarios Hyg. fab. 129 zufolge Gastgeber des Dionysos ist und von diesem in der Kunst der Weinkultivierung unterwiesen wird, vgl. D'Ippolito (1964) $152-163$.

123 Zu Ambrosia vgl. Chuvin (1991) 256f.; Gonnelli (2003) 411 - 415; Hernández de la Fuente (2008) 132 - 139. - Ähnlich wie Lykurg wird in Nonn. D. 35,353 - 366 auch der Inderkönig Deriades in Fesseln aus Weinranken gelegt.

124 Eine wesentliche Funktion kommt den Weinranken auch bei der Überwältigung der tyrrhenischen Piraten zu; Dionysos lässt ihr Schiff von Weinranken und Zypressen überwuchern und mit wilden Tieren bevölkern (Nonn. D. 45,137-151).

125 Keydell (1932) 202.

126 Daran angeschlossen werden können mehrere Szenen der Heilung und Genesung: Ino wird vom Wahnsinn geheilt (Nonn. D. 9,275-289), Aristaios heilt mit Honig und Wein (17,357-384), Lykurg wird durch Hera wieder zum Leben erweckt (21,148 ff.), die Söhne des Aretos werden geheilt $(26,268$ - 
Auch der auf dem Schild des Dionysos dargestellte Tylos-Mythos greift dieses Thema auf (Nonn. D. 25,451-552): ${ }^{127}$ Im lydischen Lokalmythos wird der durch einen Schlangenbiss zu Tode gekommene Tylos von seiner Schwester Moria durch die Anwendung eines magischen Krautes wieder zum Leben erweckt (Nonn. D. 25,539-552), nachdem zuvor die getötete Schlange mithilfe einer zweiten Schlange durch ebendieses Mittel wiederauferstanden ist (529-538). Die Szene der Auferweckung des Tylos bietet eine detailgenaue Beschreibung der einzelnen Körperteile, denen wieder Leben eingehaucht wird (Nonn. D. 25,539-552):

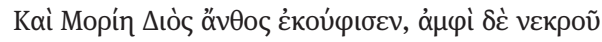

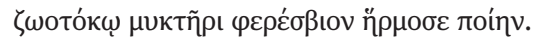

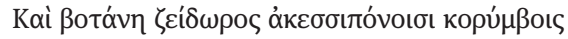

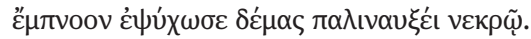

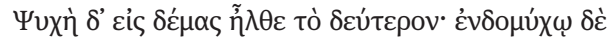

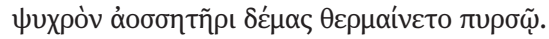

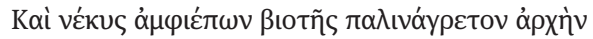

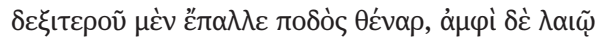

545

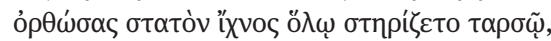

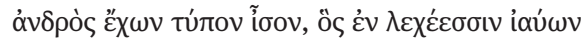

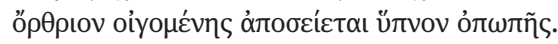

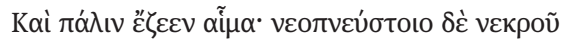

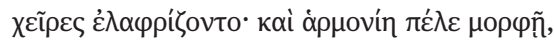

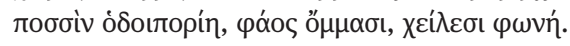

Und Moria hob die Blume des Zeus auf, und um (540) die Lebensatem spendende Nase des Toten trug sie das Leben bringende Kraut auf. Und die Nährstoffe der Pflanze mit ihren schmerzmindernden Blüten belebten den Atem im Körper und ließen den Toten wieder aufleben. Die Seele kam zum zweiten Mal in den Körper: Und mithilfe des inneren Feuers erwärmte sich der erkaltete Körper; (545) der Tote, bemüht um den wiederkehrenden Anfang des Lebens, bewegte die Sohle des rechten Fußes, und mit dem linken richtete er sich auf und gewann mit dem ganzen Fuß einen festen Stand. Er bot ein Bild ähnlich einem Mann, der im Bett ruht und am Morgen die Augen öffnet und den Schlaf abschüttelt. (550) Und das Blut wallte wieder auf. Die Hände des neuerlich atmenden Toten hoben sich in die Höhe; und gleichmäßige Regung kam in die Gestalt, Bewegung in die Füße, Licht in die Augen, Stimme in die Lippen.

Die soteriologische Bedeutungsebene des Tylos-Mythos wird in ähnlicher Weise auch im Schicksal des Ampelos greifbar. Nonnos versetzt das Geschehen in beiden Fällen an die lydischen Flüsse Hermos und Paktolos und liefert nicht nur einen vergleichbaren erzählerischen Rahmen, sondern bietet auch Wortmaterial, das aus der Ampelos-

290), die Bakchen werden durch Wein geheilt $(29,264-275)$, Tektaphos wird von seiner Tochter gerettet (26,101-145; 30,127-186), Phönix ersteht wieder aus dem Feuer (40,396f.), Chalkomedes wird von der Liebe geheilt (34,69 - 73), Morrheus wird durch einen Brahmanen geheilt (39,356 - 360), vgl. Hernández de la Fuente (2008) 215-225.

127 Zur Tylos-Episode bei Nonnos vgl. Chuvin (1991) 106-111; Shorrock (2001) 176; Espinar Ojeda u. Hernández de la Fuente (2002); Hernández de la Fuente (2008) 183-205; Agnosini (2010); Hernández de la Fuente (2013a) 479f.; Spanoudakis (2013); Spanoudakis (2014a) 334-358. 


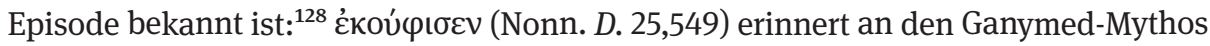

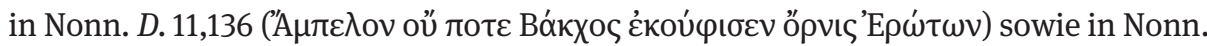

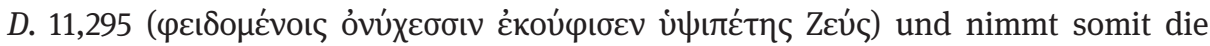

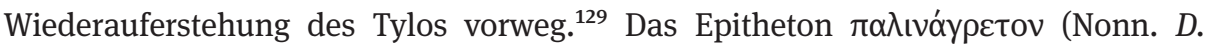
25,545) erinnert an Atropos’ Prophezeiung von Ampelos' Wiederbelebung (бòs yóos

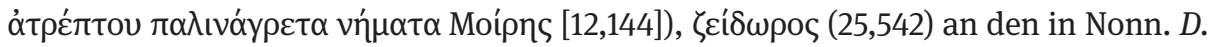

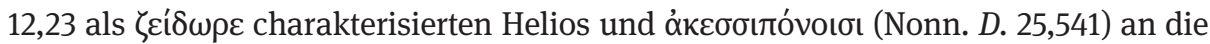

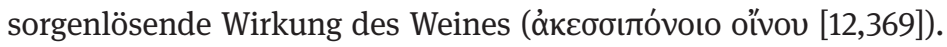

128 Vgl. Herńandez de la Fuente (2008) 188 f.

129 Die Konzentration der vorliegenden Schildbeschreibung auf die Thematik der Wiederauferstehung wird auch aus der der Tylos-Episode unmittelbar vorausgehenden Darstellung des Ganymed ersichtlich (Nonn. D. 25,429-450), vgl. dazu Agosti (2004) 122-124. 